\title{
Structurally Diverse Diazafluorene-Ligated Palladium(II) Complexes and their Implications for Aerobic Oxidation Reactions
}

\author{
Paul B. White, Jonathan N. Jaworski, Charles G. Fry, Brian S. Dolinar, Ilia A. Guzei, and \\ Shannon S. Stahl ${ }^{*}$ \\ Department of Chemistry, University of Wisconsin-Madison, 1101 University Avenue, Madison, WI \\ 53706
}

\begin{abstract}
4,5-Diazafluoren-9-one (DAF) has been identified as a highly effective ligand in a number of Pdcatalyzed oxidation reactions, but the mechanistic basis for its utility has not been elucidated. Here, we present the complex coordination chemistry of DAF and palladium(II) carboxylate salts. Multiple complexes among an equilibrating mixture of species have been characterized by ${ }^{1} \mathrm{H}$ and ${ }^{15} \mathrm{~N}$ NMR spectroscopy and X-ray crystallography. These complexes include monomeric and dimeric Pd ${ }^{\mathrm{II}}$ species, with monodentate $\left(\kappa^{1}\right)$, bidentate $\left(\kappa^{2}\right)$ and bridging $\left(\mu: \kappa^{1}: \kappa^{1}\right)$ DAF coordination modes. Titration studies of $\mathrm{DAF}$ and $\mathrm{Pd}(\mathrm{OAc})_{2}$ reveal the formation of two dimeric $\mathrm{DAF} / \mathrm{Pd}(\mathrm{OAc})_{2}$ complexes at low $[\mathrm{DAF}]$ and four monomeric species at higher [DAF]. The dimeric complexes feature two bridging acetate ligands together with either a bridging or nonbridging- $\kappa^{1}$ DAF ligand coordinated to each $\mathrm{Pd}^{\mathrm{II}}$ center. The monomeric structures consist of three isomeric $\mathrm{Pd}\left(\kappa^{1}-\mathrm{DAF}\right)_{2}(\mathrm{OAc})_{2}$ complexes, together with $\mathrm{Pd}\left(\kappa^{2}-\mathrm{DAF}\right)(\mathrm{OAc})_{2}$ in which the DAF exhibits a traditional bidentate coordination mode. Replacing DAF with the structurally related, but more-electron-rich derivative 9,9-dimethyl-4,5-diazafluorene ( $\left.\mathrm{Me}_{2} \mathrm{DAF}\right)$ simplifies the equilibrium mixture to two complexes, a dimeric species in which the $\mathrm{Me}_{2} \mathrm{DAF}$ bridges the two Pd centers and a monomeric species with a traditional $\kappa^{2}-\mathrm{Me}_{2} \mathrm{DAF}$ coordination mode. The use of DAF in combination with other carboxylate ligands $\left(\mathrm{CF}_{3} \mathrm{CO}_{2}{ }^{-}\right.$or $\left.t \mathrm{BuCO}_{2}^{-}\right)$also results in a simplified collection of equilibrating PdII-DAF complexes. Collectively, the results highlight the ability of DAF to equilibrate rapidly among multiple coordination modes, and provide valuable insights into the utility of DAF as a ligand in Pd-catalyzed oxidation reactions.
\end{abstract}

\section{Introduction}

The renaissance of Pd-catalyzed aerobic oxidation reactions over the past 10-15 years can be attributed, at least in part, to the identification of ancillary ligands that have enabled new synthetic transformations and support improved catalyst activity, selectivity, and stability. ${ }^{1}$ The ligands tune catalyst sterics and electronics, and thereby influence elementary steps,

*Corresponding Author, stahl@chem.wisc.edu. ASSOCIATED CONTENT

Supporting Information. Experimental and computational details, NMR spectra, exchange measurements and crystallography reports are available free of charge via the Internet at http://pubs.acs.org. 
such as ligand substitution, $\beta$-hydride elimination, and reductive elimination, and provide the basis for catalyst-controlled regio- and stereoselective transformations. Continued identification and/or development of new ligands remains a crucial goal to reduce catalyst loadings, enhance catalyst lifetimes and promote the discovery of novel transformations.

Pd-catalyzed aerobic oxidation reactions require the use of oxidatively stable ligands. Monodentate pyridine derivatives are especially common; ${ }^{2}$ however, catalysts containing these ligands are often susceptible to decomposition, especially at elevated temperatures. ${ }^{3}$ Catalyst stability can be enhanced through the use of bidentate ligands, such as 2,2'bipyridine (bpy) and 1,10-phenanthroline (phen) derivatives. These ligands have been used effectively in Pd-catalyzed aerobic oxidation reactions, although the results are typically observed in polar solvents (e.g., $\mathrm{H}_{2} \mathrm{O}$, DMSO, DMF) ${ }^{4}$ or at high temperatures (120$\left.200{ }^{\circ} \mathrm{C}\right),{ }^{5}$ which are often needed to enable anionic ligand dissociation from $(\mathrm{N} \sim \mathrm{N}) \mathrm{PdX} \mathrm{X}_{2}$ species to access open coordination at the $\mathrm{Pd}^{\mathrm{II}}$ center. Under mild conditions and/or in nonpolar solvents, bidentate ligands such as bpy and phen often strongly inhibit Pd-catalyzed aerobic oxidation reactions. ${ }^{6,7}$

4,5-Diazafluoren-9-one (DAF) is a rare exception to the observations just noted. In 2010, we reported that DAF is a uniquely active bipyridine-type ligand in Pd-catalyzed allylic acetoxylation of terminal olefins. ${ }^{7}$ Other bidentate ligands, such as bpy and phen, were found to strongly inhibit the reaction. Subsequent to this discovery, DAF has been used in numerous other Pd-catalyzed reactions, including oxidative $\mathrm{C}-\mathrm{C}$ and $\mathrm{C}-\mathrm{O}$ coupling reactions of arenes, ${ }^{8}$ dehydrogenation of cyclic ketones ${ }^{9}$ and oxidative Heck reactions. ${ }^{10,11}$ The unique behavior of DAF, relative to bpy and phen, in several of these reactions is illustrated in Scheme 1.

The beneficial effect of DAF in these reactions could arise from its unique coordination properties relative to more-traditional bidentate nitrogen ligands. Evidence of unusual DAF coordination chemistry are evident from previously reported complexes with first-row transition metals, ${ }^{12}$ palladium( $(0),{ }^{13}$ and other examples ${ }^{14}$ in which pentahapto $\left(\eta^{5}\right)$, bridging $(\mu)$ and monodentate $\left(\kappa^{1}\right)$, in addition to traditional bidentate, coordination modes have been identified. On the other hand, previously reported $\mathrm{DAF} / \mathrm{Pd}^{\mathrm{II}}$ complexes are limited to two examples (Scheme 2), ${ }^{15}$ both of which exhibit the canonical bidentate coordination mode.

In the present study, we show that the DAF/Pd ${ }^{\mathrm{II}}$ coordination chemistry is much richer and more complex than the structures in Scheme 2 might suggest. Through the use of multinuclear NMR spectroscopy, single crystal X-ray diffraction analysis and density functional theory (DFT) calculations, we have identified and characterized six independent coordination complexes that arise from the combination of DAF and $\mathrm{Pd}(\mathrm{OAc})_{2}$. These complexes include both monomeric and dimeric structures, in which DAF exhibits $\kappa^{1}, \kappa^{2}$, and $\mu$ coordination modes. Complementary studies with the structurally similar 9,9dimethyl-4,5-diazaflourene ( $\left.\mathrm{Me}_{2} \mathrm{DAF}\right)$ ligand provide insight into the effect of electronic perturbation of the diazafluorene ligand framework. Finally, the synergy between the coordination properties of DAF and the anionic carboxylate ligand is probed by replacing acetate with sterically and electronically different carboxylates, trifluoroacetate (TFA) and pivalate (OPiv). The unique coordination properties of DAF identified herein are compared 
to other bidenate ligands, and they are proposed to contribute directly with the beneficial, ligand-acceleration effect of DAF in $\mathrm{Pd}^{\mathrm{II}}$-catalyzed oxidation reactions. This hypothesis is validated in a companion study, in which we compare the mechanistic influence of several different bidentate ligands in Pd-catalyzed aerobic aza-Wacker reactivity and show that the fluxionality and weak coordination of DAF relative to other traditional bidentate ligands underlies its activation of $\mathrm{Pd}^{\mathrm{II}}$ catalysts. ${ }^{16}$

\section{Results}

\section{$\mathrm{DAF}: \operatorname{Pd}(\mathrm{OAc})_{2}$ Titration Experiments}

${ }^{1} \mathrm{H}$ NMR spectroscopic analysis of a 1:1 mixture of DAF and $\mathrm{Pd}(\mathrm{OAc})_{2}$ in $\mathrm{CDCl}_{3}$ reveals the presence of a complex mixture of species (Figure 1). This spectrum contrasts the spectra obtained from 1:1 mixtures of $\mathrm{Pd}(\mathrm{OAc})_{2}$ and more typical bidentate nitrogen ligands, such as 4,4'- $t \mathrm{Bu}_{2}$ bpy and 2,9- $\mathrm{Me}_{2}$ phen (Figure 1). The latter solutions feature single $\mathrm{Pd}\left(\kappa^{2}-\mathrm{N} \sim \mathrm{N}\right)$ $(\mathrm{OAc})_{2}$ species, which have been described previously in the literature. ${ }^{17}$

In an effort to begin identifying the species present in the 1:1 DAF:Pd(OAc) ${ }_{2}^{1} \mathrm{H}$ NMR spectrum, we performed a titration experiment in which different quantities of DAF were added to a solution of $\mathrm{Pd}(\mathrm{OAc})_{2}$ (Figure $2 \mathrm{~A}$ ). The most diagnostic region of the ${ }^{1} \mathrm{H}$ NMR spectrum is from 8.6-10.9 ppm, where the ortho protons of the DAF ligand appear. With 0.5 equiv of DAF, a single peak assigned to species A predominates in this region of the spectrum. At 1 equiv of DAF, several pairs of resonances are evident, with the major pair designated as species $\mathbf{B}$. The pairs of resonances are attributed to $\mathrm{Pd}^{\mathrm{II}}$ complexes with unsymmetrically coordinated DAF ligands. Free DAF is also present in this spectrum. When $\geq 2$ equiv of DAF are added, only small quantities of $\mathbf{A}$ and $\mathbf{B}$ are present, and the spectra reveal four new species, three with unsymmetrical DAF ligands, $\mathbf{C}-\mathbf{E}$, and one with a symmetrical DAF ligand, F. The growth and/or decay of each of these species were tracked as a function of DAF equivalents (Figure 2C). This plot provided the conditions under which the concentration of individual species could be maximized to facilitate more-thorough structural characterization.

The nomenclature employed for the spectral assignments is presented in Figure 2B. Within a given complex, protons belonging to each DAF ligand are labeled with the lower-case letter of the complex name, a-f. A superscript " 0 " is used to designate resonances associated with a symmetrical DAF ligand in which both pyridyl rings are coordinated to Pd. For complexes with monodentate $\left(\kappa^{1}\right)$ DAF ligands, a superscript "1" is used to designate the coordinated ring, and a superscript "2" for the uncoordinated ring. Finally, subscripts $o, m$, and $p$ are used to designate the ortho, meta, and para protons.

\section{Overview of Methods Used to Characterize DAF/Pd(OAc) $)_{2}$ Complexes}

The integration of the ${ }^{1} \mathrm{H}$ NMR peaks together with selective 1D TOCSY, ${ }^{18} 1 \mathrm{D}$ and 2D ROESY ${ }^{19}$ and $2 \mathrm{D}{ }^{1} \mathrm{H}-{ }^{15} \mathrm{~N}$ HMBC ${ }^{20}$ experiments provided key insights into the identity of complexes A-F (Scheme 3). The 1D TOCSY experiments enabled assignment of the ortho, meta, and para protons within individual rings of the DAF ligand, even when significant overlap was present among resonances from different complexes. The ROESY experiments 
revealed through-space interactions between ligands within the Pd coordination sphere, including DAF $\leftrightarrow \mathrm{DAF}$ and $\mathrm{DAF} \leftrightarrow \mathrm{OAc}$ interactions. ROESY experiments were used in place of NOESY experiments at lower temperature because the NOE sign and intensity depend on temperature and molecular size, and use of NOESY led to false-negative results. These data, together with integration of the DAF and OAc resonances, were used to determine the DAF:OAc:Pd stoichiometry for each of the complexes A-F.

The ${ }^{1} \mathrm{H}^{15} \mathrm{~N}$ HMBC experiment provided a means to determine the ${ }^{15} \mathrm{~N}$ chemical shift of the DAF nitrogen atoms without isotopic enrichment, and this experiment clearly distinguished between coordinated and uncoordinated nitrogen atoms. Uncoordinated pyridine ligands exhibit ${ }^{15} \mathrm{~N}$ chemical shifts at $\sim 300 \mathrm{ppm}$, whereas $\mathrm{Pd}^{\mathrm{II}}$-coordinated pyridine ligands appear at $\sim 200 \mathrm{ppm}$ (Scheme 4). ${ }^{21}$ These differences allowed distinction between monodentate and bidentate DAF coordination modes.

The NMR spectroscopic data were complemented by X-ray crystallography, which provided solid-state structural information that could be compared to the solution-phase NMR data. Finally, DFT calculations facilitated structural assignment of the closely related structures $\mathbf{C}-\mathbf{E}$. Application of these techniques to determine the identity of complexes A-F is elaborated below.

\section{Structural Assignment of A}

The first species evident in the ligand titration is complex A. As mentioned previously, A grows to its maximum concentration at 0.5 equiv DAF relative to $\mathrm{Pd}(\mathrm{OAc})_{2}$. The TOCSY experiment correlates a single set of ortho, meta, and para resonances, indicating that the two DAF pyridyl rings are equivalent in A (Figure 3A, Figure S2). The ${ }^{1} \mathrm{H}_{-}{ }^{15} \mathrm{~N}$ HMBC spectrum reveals a single ${ }^{15} \mathrm{~N}$ resonance at $204 \mathrm{ppm}$, indicating that $\mathbf{a}_{\boldsymbol{o}}{ }_{\boldsymbol{o}}$ and $\mathbf{a}^{\mathbf{0}}{ }_{\boldsymbol{m}}$ are associated with a coordinated pyridyl ligand (Figure 3B). The presence of both ${ }^{2} J_{\mathrm{NH}}$ and ${ }^{3} J_{\mathrm{NH}}$ cross-peaks in the HMBC spectrum complements the results from the TOCSY experiment and confirms that the resonances belong to the same complex.

The integrated 1D ${ }^{1} \mathrm{H}$ NMR spectrum of $\mathbf{A}$ reveals a DAF:OAc stoichiometry of 1:4, and a 1D ROESY experiment shows through-space interactions between the DAF ligand and two chemically distinct acetate ligands (Scheme 5, Figure S5). Integration of the two acetate resonances reflects three and six protons, corresponding to a DAF:OAc ${ }^{1}: \mathrm{OAc}^{2}$ ratio of 1:1:2. A third acetate peak is evident in the $1 \mathrm{D}{ }^{1} \mathrm{H}$ NMR spectrum, which has an integration of three protons. This third acetate resonance does not appear in the ROESY spectra (Figure S5), however, suggesting that it is too distant from DAF to observe an ROE. ${ }^{22}$

Crystals suitable for single crystal X-ray analysis were obtained from a 0.5:1 DAF:Pd(OAc) $)_{2}$ mixture in $\mathrm{CDCl}_{3}$, and the structure reveals a $C_{\mathrm{s}}$-symmetric $\mathrm{Pd}^{\mathrm{II}}$ dimer with a one DAF and two acetate ligands bridging the two Pd atoms (Figure 4). Each of the Pd centers has an additional monodentate $\left(\kappa^{1}\right)$ acetate ligand, which are eclipsed with respect to the Pd-Pd axis. This structure is consistent with the NMR data, and redissolution of the crystals in $\mathrm{CDCl}_{3}$ reproduces the spectrum of $\mathbf{A}$ present in the 0.5:1 DAF:Pd(OAc) $)_{2}$ solution. 
This structure exhibits a mirror plane perpendicular to the $\mathrm{Pd}-\mathrm{Pd}$ axis that rationalizes the chemical equivalence of two pyridyl rings of the DAF ligand evident in the $1 \mathrm{D}{ }^{1} \mathrm{H}$ NMR spectrum. It also accounts for the ${ }^{1} \mathrm{H}_{-}{ }^{15} \mathrm{~N}$ HMBC data showing that both DAF pyridyl rings are coordinated to $\mathrm{Pd}$. The $\mu-\mathrm{OAc}$ and two $\kappa^{1}-\mathrm{OAc}$ ligands adjacent to the DAF ligand are the origin of the observed ROEs. The $\mu$-OAc trans to the DAF ligand is too far from the DAF protons to be detected by the ROESY experiment. ${ }^{23}$

\section{Structural Assignment of B}

Addition of more DAF to the solution of $\mathbf{A}$ results in conversion to $\mathbf{B}$. Analysis of the NMR data revealed that $\mathbf{B}$ has a DAF ligand with two chemically distinct pyridyl rings, $\mathbf{b}^{\mathbf{1}}$ and $\mathbf{b}^{\mathbf{2}}$ (Figure 5A). A Pd-bound pyridyl ring $\left(\mathbf{b}^{\mathbf{1}}\right)$ is clearly evident from the ${ }^{15} \mathrm{~N}$ resonance at 189 ppm, and an unbound ring $\left(\mathbf{b}^{2}\right)$ is associated with the resonance at 305 ppm (Figure 5B).

The 2D ROESY spectrum reveals two acetate cross-peaks, indicating that $\mathbf{B}$ contains chemically inequivalent acetate ligands (Figures S6 and S7). Furthermore, ROEs are observed from $\mathbf{b}^{\mathbf{1}}$ and $\mathbf{b}^{\mathbf{2}}$ to both of these acetates, demonstrating that $\mathbf{b}^{\mathbf{1}}$ and $\mathbf{b}^{\mathbf{2}}$ are present in the same complex (i.e., $\mathbf{B}=\mathbf{b}^{\mathbf{1}}+\mathbf{b}^{\mathbf{2}}$ ) (Scheme 6). These conclusions are supported by 1D ROESY experiments in which ROEs were observed between each of the acetate resonances and the $\mathbf{b}_{\mathbf{o}_{\mathbf{0}}}$ and $\mathbf{b}^{\mathbf{2}}{ }_{\mathbf{0}}$ ring resonances (Figure S8). Integration of the DAF and OAc resonances in the $1 \mathrm{D}^{1} \mathrm{H}$ NMR spectrum reveals a DAF:OAc stoichiometry of 1:2.

Crystals suitable for single crystal X-ray analysis were obtained from a 1.5:1 DAF:Pd(OAc) $)_{2}$ mixture in $\mathrm{CDCl}_{3}$, and the structure reveals a $C_{2}$-symmetric $\mathrm{Pd}^{\mathrm{II}}$ dimer with two acetate ligands bridging the Pd atoms (Figure 6). Each Pd center is also coordinated by a $\kappa^{1}$-DAF and a $\kappa^{1}$-OAc ligand.

This structure has a $C_{2}$ axis perpendicular to the $\mathrm{Pd}-\mathrm{Pd}$ axis that bisects the two bridging acetate ligands, rationalizing the chemical equivalence of the two $\kappa^{1}$-DAF ligands and the pairs of $\mu$ - and $\kappa^{1}$-OAc ligands evident in the $1 \mathrm{D}{ }^{1} \mathrm{H}$ NMR spectrum. This structure also explains the ${ }^{1} \mathrm{H}_{-}{ }^{15} \mathrm{~N}$ HMBC data showing both bound and unbound DAF pyridyl rings. The ROESY data showing through-space interactions between DAF and two chemically distinct acetate ligands are also readily rationalized by this structure.

\section{Structural Assignment of C, D, and E}

Addition of more DAF results in the conversion of species $\mathbf{A}$ and $\mathbf{B}$ into a mixture of four new species $\mathbf{C}-\mathbf{F}$. At a DAF: $\mathrm{Pd}(\mathrm{OAc})_{2}$ ratio of 6:1, seven resonances associated with the ortho protons of the DAF ligand are present in the ${ }^{1} \mathrm{H}$ NMR spectrum, together with four distinct OAc peaks (Figures 7A, S9 and S11). Six of the seven DAF resonances correspond to three pairs of peaks with 1:1 integration, and they are assigned to species $\mathbf{C ,} \mathbf{D}$, and $\mathbf{E}$. The remaining resonance is assigned to $\mathbf{F}$ and will be discussed separately below. The concentrations of $\mathbf{C ,} \mathbf{D}$, and $\mathbf{E}$ exhibit a squared dependence on the DAF concentration, suggesting that these structures exhibit a 2:1 DAF:Pd stoichiometry (cf. Figure 2C). The ${ }^{1} \mathrm{H}_{-}{ }^{15} \mathrm{~N}$ HMBC spectrum reveals six cross-peaks for $\mathbf{C}, \mathbf{D}$, and $\mathbf{E}$ (Figure 7B), with $\mathbf{c}^{\mathbf{1}}$, $\mathbf{d}^{\mathbf{1}}$, and $\mathbf{e}^{\mathbf{1}}$ corresponding to Pd-bound DAF pyridyl rings ( $\delta$ 203-207 ppm) and $\mathbf{c}^{\mathbf{2}}, \mathbf{d}^{\mathbf{2}}$, and $\mathbf{e}^{\mathbf{2}}$ 
corresponding to unbound rings ( $\delta 304-310 \mathrm{ppm})$. These data indicate that each of the complexes $\mathbf{C}, \mathbf{D}$, and $\mathbf{E}$ contains DAF ligands bound in a $\kappa^{1}$ coordination mode.

1D ROESY spectra for each complex reveal through-space interactions between each of the two (inequivalent) DAF ortho protons and a single acetate resonance (Scheme 7A and Figures S9 and S10). Furthermore, integrations of the DAF and OAc resonances reveal a DAF:OAc ratio of 1:1 for each complex. The 1D ROESY experiments also reveal throughspace interactions between the chemically inequivalent DAF ortho protons in $\mathbf{C}$ and $\mathbf{E}$ (i.e.,

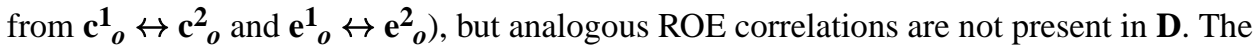
distance between the ortho protons within an individual DAF ligand $(d \sim 7.0 \AA)$ is too large to show an ROE; however, these signals can arise from interactions between two separate DAF ligands within the same complex. Computational modeling confirms that two DAF ligands with an anti relationship have ortho protons with sufficient proximity to exhibit an ROE correlation (Scheme 7B and Figures S9 and S10). No ROE correlation is expected for two DAF ligands with a syn relationship.

Four possible isomeric structures, 1-4, satisfy the constraints of the NMR spectroscopic data of species $\mathbf{C}, \mathbf{D}$, and $\mathbf{E}$ (Table 1) and correspond to $\mathrm{Pd}\left(\kappa^{1}-\mathrm{DAF}\right)_{2}(\mathrm{OAc})_{2}$ complexes that are distinguished by cis vs. trans and syn vs. anti relationships between two $\kappa^{1}$ DAF ligands in the Pd coordination sphere. The viability of these structures is supported by X-ray crystallographic characterization of one of these complexes (Figure 8). The X-ray quality crystals were obtained from a 6:1 DAF: $\mathrm{Pd}(\mathrm{OAc})_{2}$ mixture in $\mathrm{CDCl}_{3}$.

The relative energies of structures 1-4 were assessed by performing DFT computations. ${ }^{24}$ Structures 1-3 are within $1.6 \mathrm{kcal} / \mathrm{mol}$ of each other, with $\mathbf{1}$ having the lowest energy.

Structure 4, however, is significantly higher in energy $(\Delta G=+6.0 \mathrm{kcal} / \mathrm{mol}$ relative to 1$)$ and would have a population that would not be detected by NMR spectroscopy (Table 1). The higher energy of this complex may be rationalized by the steric clash between the cis/syn relationship between the two DAF ligands. These data suggest the three species detected in solution consist of a mixture of structures $\mathbf{1 , 2}$ and $\mathbf{3}$.

ROESY experiments reveal chemical exchange between $\mathbf{D}$ and $\mathbf{E}$ (Scheme 8A and Figure S9). The exchange process converts one of the DAF ortho protons in $\mathbf{D}\left(\mathbf{d}^{\mathbf{1}}{ }_{\boldsymbol{o}}\right)$ into an equal mixture of the two ortho protons in $\mathbf{E}\left(\mathbf{e}_{\boldsymbol{o}}^{\mathbf{1}}\right.$ and $\mathbf{e}^{\mathbf{2}}{ }_{\boldsymbol{o}}$ ). The temperature dependence of this exchange process was used to estimate an activation energy of $\Delta G^{\natural}=13 \pm 0.5 \mathrm{kcal} / \mathrm{mol}$ (Figure S12-13). ${ }^{25}$ These observations may be rationalized by an intramolecular exchange process that interconverts the trans/syn and trans/anti bis-DAF complexes 1 and $\mathbf{2}$ (cf. Table 1). A mechanism for this process was identified by DFT methods, and the calculated barrier is $11 \mathrm{kcal} / \mathrm{mol}$, which is in good agreement with the experimental value.

Together, the ROESY and DFT computational data enable structural assignment of complexes $\mathbf{C}, \mathbf{D}$, and $\mathbf{E}$. The DAF $\leftrightarrow$ DAF ROEs observed for $\mathbf{C}$ and $\mathbf{E}$ (cf. Scheme 7) require an anti relationship between the DAF ligands and thereby limit these species to structures 2 and $\mathbf{3}$ (cf. Table 1). The chemical exchange between $\mathbf{D}$ and $\mathbf{E}$ permits assignment of complex $\mathbf{E}$ to the trans/anti structure $\mathbf{2}$ and complex $\mathbf{D}$ to the trans/syn structure $\mathbf{1}$. Structure $\mathbf{4}$ is not believed to be among the observed structures on the basis of the DFT energy and, therefore, 
complex $\mathbf{C}$ is assigned to the cis/anti structure $\mathbf{3}$. These assignments are supported by comparison of the ${ }^{1} \mathrm{H}$ NMR chemical shifts of the acetate $-\mathrm{CH}_{3}$ groups for these three complexes with the general trends observed in chemical shifts of cis- and trans-acetate ligands. ${ }^{26}$

\section{Structural Assignment of $\mathbf{F}$}

Complex $\mathbf{F}$ appears together with $\mathbf{C ,} \mathbf{D}$, and $\mathbf{E}$ as the DAF concentration increases. Unlike

C-E, however, its concentration increases with a linear, rather than squared, dependence on DAF concentration, suggesting that it has a 1:1 DAF:Pd(OAc) $)_{2}$ stoichiometry (cf. Figure 2C). The $1 \mathrm{D}{ }^{1} \mathrm{H}$ NMR spectrum for $\mathbf{F}$ reveals a symmetrical DAF ligand, and ${ }^{1} \mathrm{H}_{-}{ }^{13} \mathrm{C}$ HSQC, variable temperature and 1D TOCSY data show that the resonances at $8.66 \mathrm{ppm}$ corresponds to both ortho and para protons ( $\mathbf{f}_{\boldsymbol{o} / \boldsymbol{p}}$ in Figure 7A; see also Figures S17-19). 1D ROESY data reveal a through-space interaction between the ortho proton of DAF and an acetate ligand, and integration of the acetate peak reveals a DAF:OAc stoichiometry of 1:2 (Figure S11). Finally, the ${ }^{1} \mathrm{H}_{-}{ }^{15} \mathrm{~N}$ HMBC spectrum (cf. Figure 7B) exhibits only a single cross-peak for $\mathbf{F}$ at $213.3 \mathrm{ppm}$, showing that the symmetrical pyridyl rings of the DAF ligand are coordinated to Pd. The monomeric structure in Scheme 9 is consistent with all of these data.

\section{Characterization of $\mathrm{Me}_{2} \mathrm{DAF} / \mathrm{Pd}(\mathrm{OAc})_{2}$ and $\mathrm{DAF} / \mathrm{Pd}\left(\mathrm{O}_{2} \mathrm{CR}\right)\left(\mathrm{R}=\mathrm{CF}_{3}, t \mathrm{Bu}\right)$ Complexes}

Several variants of the $\mathrm{DAF} / \mathrm{Pd}(\mathrm{OAc})_{2}$ catalyst system have been used in catalytic aerobic oxidation reactions. For example, as shown in Scheme 1, DAF has been replaced with 9,9dimethyl-4,5-diazafluorene $\left(\mathrm{Me}_{2} \mathrm{DAF}\right)$ and acetate has been replaced with trifluoroacetate (TFA) or pivalate (OPiv) (cf. Scheme 1). ${ }^{8,9}$ In an effort to assess the potential influence of these catalyst modifications, we investigated $\mathrm{Me}_{2} \mathrm{DAF} / \mathrm{Pd}(\mathrm{OAc})_{2}, \mathrm{DAF} / \mathrm{Pd}(\mathrm{TFA})_{2}$, and DAF/ $\mathrm{Pd}(\mathrm{OPiv})_{2}$ in a manner analogous to $\mathrm{DAF} / \mathrm{Pd}(\mathrm{OAc})_{2}$.

\section{$\mathrm{Me}_{2} \mathrm{DAF} / \mathrm{Pd}(\mathrm{OAc})_{2}$}

Titration of $\mathrm{Me}_{2} \mathrm{DAF}$ into a solution of $\mathrm{Pd}(\mathrm{OAc})_{2}$ reveals the formation of only two species $\mathbf{G}$ and $\mathbf{H}$, and only $\mathbf{H}$ is observed when $>1$ equiv of $\mathrm{Me}_{2} \mathrm{DAF}$ is present, relative to $\mathrm{Pd}(\mathrm{OAc})_{2}$ (Figure 9). The simplicity of this mixture contrasts with the complex speciation observed with $\mathrm{DAF} / \mathrm{Pd}(\mathrm{OAc})_{2}$ (cf. Figure 2). Full NMR spectroscopic analysis of these species was performed (see Supporting Information, Figures S20-S25). TOCSY data reveal that the $\mathrm{Me}_{2} \mathrm{DAF}$ ligand in both $\mathbf{G}$ and $\mathbf{H}$ have equivalent pyridyl rings, and ${ }^{1} \mathrm{H}_{-}{ }^{15} \mathrm{~N} H M B C$ data reveal a single ${ }^{15} \mathrm{~N}$ resonance for each complex, with chemical shifts in a region associated with bound $N$ atoms: 199.4 ppm (G) and $209.7 \mathrm{ppm}(\mathbf{H})$. For $\mathbf{G}$, an ROE correlation was observed between the DAF ligand and two chemically distinct acetates, designated $\mathrm{OAc}^{1}$ and $\mathrm{OAc}^{2}$, and another between $\mathrm{OAc}^{2}$ and a third acetate ligand, $\mathrm{OAc}^{3}$. Integration of the $1 \mathrm{D}^{1} \mathrm{H}$ NMR spectrum of $\mathbf{G}$ reveals a DAF:OAc stoichiometry of 1:4, with a DAF:OAc ${ }^{1}: \mathrm{OAc}^{2}: \mathrm{OAc}^{3}$ ratio of 1:1:2:1. In contrast, the acetate ligands in $\mathbf{H}$ are equivalent and the DAF:OAc stoichiometry is 1:2.

Crystals of $\mathbf{G}$ and $\mathbf{H}$ suitable for single crystal X-ray analysis were obtained from chloroform solutions of 0.5:1 and 1:1 $\mathrm{Me}_{2} \mathrm{DAF}: \mathrm{Pd}(\mathrm{OAc})_{2}$, respectively, and the resulting structures are consistent with the solution NMR data (Figure 10). $\mathbf{G}$ is a dimeric species with 
a bridging $\mathrm{Me}_{2} \mathrm{DAF}$ ligand and two bridging and two $\kappa^{1}$ acetate ligands, matching the DAF/ $\mathrm{Pd}(\mathrm{OAc})_{2}$ structure $\mathbf{A}$ (cf. Figure 4). $\mathbf{H}$ is a monomeric species with the $\mathrm{Me}_{2} \mathrm{DAF}$ ligand in a traditional $\kappa^{2}$ bidentate coordination mode, analogous to the $\mathrm{DAF} / \mathrm{Pd}(\mathrm{OAc})_{2}$ structure $\mathbf{F}$.

\section{DAF/Pd(TFA) 2}

$\operatorname{Pd}(\mathrm{TFA})_{2}$ is insoluble $\mathrm{CDCl}_{3}$, but it dissolves in a 1:1 ratio of $\mathrm{CDCl}_{3}$ and trifluoroacetic acid (TFAH). Titration of DAF into a solution of Pd(TFA $)_{2}$ in this solvent mixture reveals the sequential appearance of three species, I, J, and $\mathbf{K}$ (Figure 11), each of which was extensively characterized by NMR spectroscopic methods (see Supporting Information, Figures S28-S32). Complex I maximizes at 0.5:1 DAF:Pd(TFA) $)_{2}$ stoichiometry, but coexists with $\mathbf{J}$. Complex $\mathbf{J}$ is essentially the only species present at a 1:1 DAF:Pd(TFA) 2 stoichiometry, while it begins to disappear in favor of $\mathbf{K}$ at higher DAF concentrations. It was possible to obtain X-ray crystal structures of $\mathbf{I}$ and $\mathbf{J}$ (Figure 12), and the solid-state structures are consistent with the solution NMR data. Complex $\mathbf{I}$ is the dimeric species $\mathrm{Pd}_{2}\left(\mu\right.$-DAF) $(\mu \text {-TFA) })_{2}\left(\kappa^{1}-\mathrm{TFA}\right)_{2}$, which resembles structures $\mathbf{A}$ and $\mathbf{G}$ above (cf. Figures 4 and 10$)$, while $\mathbf{J}$ is the monomeric structure $\operatorname{Pd}\left(\kappa^{2}-\mathrm{DAF}\right)\left(\kappa^{1}-\mathrm{TFA}\right)_{2}$, which resembles structures $\mathbf{F}$ and $\mathbf{H}$ above (Scheme 9 and Figure 10). Complex $\mathbf{K}$ only forms at high DAF concentrations, and it was not possible to obtain crystals of this complex. NMR data for this complex reveals dynamic behavior arising from rapid exchange between uncoordinated DAF and coordinated to $\mathbf{J}$ and $\mathbf{K}$. The parabolic growth of $\mathbf{K}$ with increasing [DAF] and NMR integrations are consistent with a 2:1 DAF:Pd(TFA $)_{2}$ stoichiometry, and all of the data point toward this species being a mononuclear complex with two $\kappa^{1}$-DAF ligands, $\operatorname{Pd}\left(\kappa^{1}\right.$ $\mathrm{DAF})_{2}(\mathrm{TFA})_{2}$, similar to species $\mathbf{C}, \mathbf{D}$ and $\mathbf{E}$ (cf. Table 1).

\section{$\mathrm{DAF} / \mathrm{Pd}(\mathrm{OPiv})_{2}$}

Titration of DAF into a solution of $\mathrm{Pd}(\mathrm{OPiv})_{2}$ reveals a single major DAF-ligated Pd species L at all DAF:Pd(OPiv) $)_{2}$ stoichiometries (Figure 13). Only minor $(<10 \%)$ contributions from other DAF-ligated species are evident. The NMR spectroscopic data show that the DAF and OPiv ligands are present in 1:2 stoichiometry and that the two pyridyl groups of DAF are equivalent and coordinated to Pd (see Supporting Information, Figures S33 and S34). An Xray crystal structure of $\mathbf{L}$ reveals that this complex is a $C_{2}$-symmetric dimer in which two trans DAF ligands bridge two Pd ${ }^{\mathrm{II}}$ centers, each of which also has two $\kappa^{1}$-OPiv ligands (Figure 14). ${ }^{27}$ An approximately $45^{\circ}$ twist is evident between the N-Pd-N vectors of the two $\mathrm{Pd}^{\mathrm{II}}$ centers, when the dimer is viewed down the Pd..Pd axis. This structural feature differs from the $\mathrm{DAF} / \mathrm{Pd}(\mathrm{OAc})_{2}$ dimers $\mathbf{A}$ and $\mathbf{B}$, for which the two $\mathrm{Pd}^{\mathrm{II}}$ square planes have an eclipsed relationship (i.e., $\theta=0^{\circ}$ ). Upon redissolving the crystals of $\mathbf{L}$ into $\mathrm{CDCl}_{3}$, identical spectral data are observed. It seems likely that the symmetrical monomeric structure, $\mathrm{Pd}\left(\mathrm{\kappa}^{2}-\mathrm{DAF}\right)(\mathrm{OAc})_{2}$, is disfavored by the steric bulk of the pivalate groups.

\section{Discussion}

\section{Origin of Diverse Coordination Geometries with DAF}

The results presented here highlight the structural diversity of DAF coordination to Pdcarboxylate salts. The results show that DAF exhibits bridging $(\mu), \kappa^{1}$ - and $\kappa^{2}$-binding modes when coordinated to $\mathrm{Pd}^{\mathrm{II}}$ centers bearing carboxylate anionic ligands, and most of the 
structures deviate from the classical $\kappa^{2}$-bidentate coordination mode typically associated with bipyridyl-type ligands. This rich diversity is evident in mixtures of DAF and $\mathrm{Pd}(\mathrm{OAc})_{2}$. Under conditions with 1:1 DAF: $\operatorname{Pd}(\mathrm{OAc})_{2}$ stoichiometry (a typical stoichiometry for catalytic reactions), six different structures are present in significant quantity (A-F, cf. Figure 2). The complexes are highly fluxional, but static structures suitable for NMR spectroscopic characterization were accessible at $-45^{\circ} \mathrm{C}$. Upon replacing DAF with the more electron-rich ligand $\mathrm{Me}_{2} \mathrm{DAF}$ or the acetate ligands with more electron-deficient trifluoroacetate ligands, equilibrium mixtures are still observed, but a smaller number of species are present (cf. Figures 9 and 11). The corresponding complexes are also less fluxional than the $\mathrm{DAF} / \mathrm{Pd}(\mathrm{OAc})_{2}$ species, allowing NMR spectroscopic studies to be performed at room temperature. As expected, increasing the DAF concentration promotes the formation of monomeric structures, including complexes bearing a single $\kappa^{2}$-DAF and/or two $\kappa^{1}$-DAF ligands. Only the sterically encumbered $\mathrm{Pd}(\mathrm{OPiv})_{2}$ species favors a single DAF complex at all DAF concentrations and, in this case, favors a unique dimeric Pd complex with two bridging DAF ligands.

This unique DAF/Pd-carboxylate coordination chemistry may be rationalized by the structural distortion of the DAF ligand relative to traditional bpy-type ligands. Two structural parameters that facilitate comparison of these ligands are the angle $\alpha$, defined by the $\mathrm{C} 2-\mathrm{N}$ and $\mathrm{C}^{2}-\mathrm{N}$ bond vectors of the two pyridyl rings, and the $\mathrm{N} \cdots \mathrm{N}$ distance between the two pyridyl nitrogen atoms (Scheme 10). Introduction of a one-atom linker between the 3-and $3^{\prime}$-positions of $2,2^{\prime}$-bipyridine expands a from $53^{\circ}$ in bpy to $73^{\circ}$ in the unligated bpy and DAF ligands, and similarly increases the $\mathrm{N}$... N distance from $2.66 \AA$ to $3.06 \AA$, respectively. ${ }^{28}$ The parameters for $\mathrm{Me}_{2} \mathrm{DAF}\left(73^{\circ}, 3.07 \AA\right.$ ) are nearly identical to those for DAF. ${ }^{29}$ The a angle for unligated bpy is similar to that observed in bpy-ligated complexes of $\mathrm{Pd}^{\mathrm{II}}$. For example, $\mathrm{a}=49^{\circ}$ and $54^{\circ}$ in $\mathrm{Pd}(\mathrm{bpy})(\mathrm{OAc})_{2}$ and $\mathrm{Pd}\left(2,9-\mathrm{Me}_{2}\right.$ phen $)(\mathrm{OAc})_{2}$, respectively. ${ }^{17 \mathrm{a}, \mathrm{c}}$ In contrast, the $\kappa^{2}$-DAF complexes of $\mathrm{Pd}^{\mathrm{II}}$ require significant contraction of their $\alpha$ angle relative to unligated DAF: $\alpha=61^{\circ}$ and $60^{\circ}$ in complexes $\mathbf{H}$ and $\mathbf{J}$, respectively. The $a$ angle expands considerably when DAF serves as a bridging ligand: $\alpha=82-84^{\circ}$ in complexes $\mathbf{A}, \mathbf{G}, \mathbf{I}$, and $\mathbf{L}$, while virtually no distortion is evident in the structures bearing $\kappa^{1}$-DAF ligands: $\alpha=76^{\circ}$, complexes $\mathbf{B}, \mathbf{C}, \mathbf{D}, \mathbf{E}$ (Scheme 10). Commensurate changes are evident in the $\mathrm{N} \cdots \mathrm{N}$ bond distances (Scheme 10). In short, unligated DAF exhibits structural features intermediate between the $\kappa^{2}$ (bidentate) and $\mu$ (bridging) coordinated DAF ligands, thereby enabling it to access both of these coordination modes. In addition, DAF can access the $\kappa^{1}$ coordination mode, which relieves the modest strain present in the other two modes. The small a value for unligated bpy makes it well suited for coordination to $\mathrm{Pd}^{\mathrm{II}}$ as a bidentate $\left(\kappa^{2}\right)$ ligand, but poorly suited to serve as a bridging $(\mu)$ ligand. Rare examples of $\mathrm{Pd}_{2}\left(\mu\right.$-bpy) complexes exist,${ }^{30}$ but they accommodate this coordination via a significant dihedral angle between the two pyridyl rings of the bpy ligands ( $53^{\circ}$ and $59^{\circ}$ respectively).

\section{Relevance to Aerobic Oxidation Catalysis}

The unique coordination chemistry of DAF has important implications for Pd-catalyzed aerobic oxidation reactions. The simplified mechanism of these catalytic reactions consists of two half-reactions: substrate oxidation by $\mathrm{Pd}^{\mathrm{II}}$ and catalyst reoxidation by $\mathrm{O}_{2}$ (Scheme 11). The turnover-limiting step in most (if not all) of these reactions is associated with the 
$\mathrm{Pd}^{\mathrm{II}}$-mediated substrate oxidation half-reaction and corresponds to one of various fundamental steps, such as ligand substitution (i.e., substrate binding), alkene insertion (e.g., into a $\mathrm{Pd}-\mathrm{C}$ or $\mathrm{Pd}-\mathrm{N}$ bond), $\beta$-hydride elimination or $\mathrm{C}-\mathrm{H}$ activation. Ligand steric and electronic properties influence the rate of the $\mathrm{Pd}^{\mathrm{II}}$-mediated reaction steps, and one or more ligands typically must dissociate from $\mathrm{Pd}^{\mathrm{II}}$ to provide coordination sites for substrate reactivity. Steps associated with the catalyst reoxidation half-reaction are typically fast, by comparison, but ancillary ligands still play an important role. ${ }^{31}$ Ligands not only promote the reaction of $\mathrm{O}_{2}$ with $\mathrm{Pd}^{0}$, but they also can minimize catalyst aggregation into inactive metallic Pd ("Pd-black"). ${ }^{32}$

Neutral monodentate ligands, such as pyridine, triethylamine ( $\left.\mathrm{NEt}_{3}\right)$ and DMSO, have been widely used in Pd-catalyzed aerobic oxidation reactions, ${ }^{1}$ and typical catalyst systems employ a 2:1 L:Pd ${ }^{\mathrm{II}}$ stoichiometry. Mechanistic studies have revealed that faster initial rates may be obtained with a 1:1 L:Pd ${ }^{\mathrm{II}}$ stoichiometry, which enhances substrate accessibility to the $\mathrm{Pd}^{\mathrm{II}}$ coordination sphere. ${ }^{33}$ The use of $22: 1 \mathrm{~L}: \mathrm{Pd}^{\mathrm{II}}$ stoichiometry in reported catalyst systems represents the optimal balance between catalyst activity and stability. At L:Pd ${ }^{\mathrm{II}}$ ratios $<2: 1$, the catalyst often decomposes before the reaction reaches full conversion.

Bidentate ligands are appealing because they enhance catalyst stability, but they often inhibit catalytic turnover. The chelate effect disfavors neutral ligand dissociation and, therefore, anionic ligand dissociation is required to enable substrate access to the $\mathrm{Pd}^{\mathrm{II}}$ coordination sphere. Formation of a charged complex has a strong solvent dependence, as illustrated by a recent study of amidopalladation of alkenes with a (bpy)Pd ${ }^{\mathrm{II}}$ (amidate)Cl complex (Scheme 12). ${ }^{34}$ Alkene insertion does not proceed in toluene, while it proceeds readily in DMSO at room temperature. The reaction was shown to proceed via pre-equilibrium dissociation of chloride, which is strongly inhibited in a non-polar solvent.

The structures of DAF/Pd(OAc $)_{2}$ complexes presented herein show that DAF exhibits properties of both mono- and bidentate ligands. And, the empirical success of DAF in Pdcatalyzed aerobic oxidation reactions suggests that DAF can take advantage of the beneficial features of both ligand types. The $\kappa^{1}$ coordination mode, evident in structures B-E, provides access to open coordination sites at $\mathrm{Pd}^{11}$ without requiring dissociation of an anionic ligand. This feature should stabilize intermediates and/or transition states associated with key substrate oxidation steps, such as C-H activation, alkene insertion or (3-hydride elimination (Scheme 13). ${ }^{8,10}$ On the other hand, the bidentate character of DAF evident in F, H, J, $\operatorname{Pd}(\mathrm{DAF})\left(\left.\mathrm{r}\right|^{3} \text {-allyl }\right)^{+6 \mathrm{~b}}$ and $\mathrm{Pd}(\mathrm{DAF}) \mathrm{Cl} 2^{15}$ provides a means to enhance catalyst stability upon formation of $\mathrm{Pd}^{\circ}$ in the catalytic cycle.

The principles discussed here have implications for other Pd-catalyzed oxidation reactions. Of particular note are the allylic and aromatic $\mathrm{C}-\mathrm{H}$ oxidation reactions that employ 2,2'bipyrimidine (bpm)-Pd ${ }^{\mathrm{II}}$ catalysts, reported recently by Bercaw/Labinger ${ }^{35 \mathrm{a}}$ and Yin, ${ }^{35 \mathrm{~b}}$ respectively (Scheme 14). These reactions are promoted by coordination of the bpm ligand to a second metal, $\mathrm{Pd}^{\mathrm{II}}$ or $\mathrm{Al}^{\mathrm{III}}$. This coordination could lead to a structural distortion similar to that has been characterized for DAF in the present study. ${ }^{36,37}$ Further investigation of this concept in catalytic reactions is the focus of ongoing investigation. 


\section{Conclusion}

The rich coordination chemistry of 4,5-diazafluoren-9-one (DAF)-Pd(OAc) $)_{2}$ has been characterized by diverse NMR spectroscopic methods, X-ray crystallography and DFT calculations. In particular, ${ }^{1} \mathrm{H}_{-}{ }^{15} \mathrm{~N}$ HMBC and ROESY experiments played a critical role in determining the coordination mode of the DAF ligand in solution. The data show that DAF is able to adopt bridging $(\mu)$, chelating $\left(\kappa^{2}\right)$ and monodentate $\left(\kappa^{1}\right)$ coordination modes in monomeric and dimeric $\mathrm{Pd}^{\mathrm{II}}$ complexes. Six different $\mathrm{DAF} / \mathrm{Pd}(\mathrm{OAc})_{2}$ species have been characterized and compared to analogous $\mathrm{Me}_{2} \mathrm{DAF} / \mathrm{Pd}(\mathrm{OAc})_{2}, \mathrm{DAF} / \mathrm{Pd}(\mathrm{TFA})_{2}, \mathrm{DAF} /$ $\mathrm{Pd}(\mathrm{OPiv})_{2}$ and $\mathrm{DAF} / \mathrm{Pd}\left(\mathrm{O}_{2} \mathrm{CC}_{6} \mathrm{~F}_{5}\right)_{2}$ species. The equilibrium population changes systematically as a function of [DAF], with monomeric structures favored at higher [DAF]. The hemilabile character of DAF provides a compelling rationale for the beneficial reactivity of DAF, relative to other bidentate ligands, in Pd-catalyzed aerobic oxidation reactions, and it provides a valuable foundation for future studies in this field.

\section{Supplementary Material}

Refer to Web version on PubMed Central for supplementary material.

\section{Acknowledgments}

We are grateful for financial support from the NIH (R01 GM67173). Computational resources are supported in part by the NSF (CHE-0840494). NMR instrumentation was partially funded by the NIH (S10 RR13866-01).

\section{References}

1.

For reviews, see: Stahl SS. Angew. Chem. Int. Ed. 2004; 43:3400-3420. Gligorich KM, Sigman MS.

Chem. Commun. 2009; 26:3854-3867.

2.

For representative examples, see the following: Nishimura T, Onoue T, Ohe K, Uemura S. J. Org. Chem. 1999; 64:6750-6755. [PubMed: 11674682] Fix SR, Brice JL, Stahl SS. Angew. Chem. Int. Ed. 2002; 41:164-166. Ferreira EM, Stoltz BM. J. Am. Chem. Soc. 2003; 125:9578-9579. [PubMed: 12904010] Iwasawa T, Tokunaga M, Obora Y, Tsuji Y. J. Am. Chem. Soc. 2004; 126:6554-6555. [PubMed: 15161274] Zhang Y-H, Shi B-F, Yu J-Q. J. Am. Chem. Soc. 2009; 131:5072-5074. [PubMed: 19296661] Izawa Y, Stahl SS. Adv. Synth. Catal. 2010; 352:3223-3229. [PubMed: 21399704] Izawa Y, Pun D, Stahl SS. Science. 2011; 333:209-213. [PubMed: 21659567] John LC, Gunay A, Wood AJ, Emmert MH. Tetrahedron. 2013; 69:5758-5764.

3. (a) Steinhoff BA, Guzei IA, Stahl SS. J. Am. Chem. Soc. 2004; 126:11268-11278. [PubMed: 15355108] (b) Komano T, Iwasawa T, Tokunaga M, Obora Y, Tsuji Y. Org. Lett. 2005; 7:46774679. [PubMed: 16209508] (c) Kubota A, Emmert MH, Sanford MS. Org. Lett. 2012; 14:1760 1763. [PubMed: 22409653]

4. (a) ten Brink G-J, Arends IWCE, Papadogianakis G, Sheldon RA. Appl. Catal., A. 2000:435-442. (b) Hu J, Gu Y, Guan Z, Li J, Mo W, Li T, Li G. Chem. Sus. Chem. 2011; 4:1767-1772.(c) Ye M, Gao G-L, Yu J-Q. J. Am. Chem. Soc. 2011; 133:6964-6967. [PubMed: 21491938] (d) Ben-Yahia A, Naas M, Kazzouli SE, Essassi EM, Guillaumet G. Eur. J. Org. Chem. 2012; 36:7075-7081.

5.

Ref 4b and 4c. See also: Shiotani A, Itatani H, Inagaki T. J. Mol. Catal. 1986; 34:57-66. Gasperini M, Ragaini F, Cenini S, Gallo E, Fantauzzi S. Applied Organomet. Chem. 2007; 21:782-787. 
6.

Ref 2g and the following: Andappan MMS, Nilsson P, Larhed M. Chem. Commun. 2004; 2:218-219.

Zheng CW, Wang D, Stahl SS. J. Am. Chem. Soc. 2012; 134:16496-16499. [PubMed: 22998540]

7. Campbell AN, White PB, Guzei IA, Stahl SS. J. Am. Chem. Soc. 2010; 132:15116-15119. [PubMed: 20929224]

8. (a) Campbell AN, Meyer EB, Stahl SS. Chem. Commun. 2011; 47:10257-10259.(b) Xiao B, Gong T-J, Liu Z-J, Liu J-H, Luo D-F, Xu J, Liu L. J. Am. Chem. Soc. 2011; 133:9250-9253. [PubMed: 21609019]

9. (a) Gao W, He Z, Qian Y, Zhao J, Huang Y. Chem. Sci. 2012; 3:883-886.(b) Diao T, Wadzinski TJ, Stahl SS. Chem. Sci. 2012; 3:887-891. [PubMed: 22690316] (c) Buter J, Moezelaar R, Minnaard AJ. Org. Biomol. Chem. 2014; 12:5883-5890. [PubMed: 24984187]

10. (a) Piotrowicz M, Zakrzewski J. Organometallics. 2013; 32:5709-5712.(b) Piotrowicz M, Zakrzewski J, Métivier R, Brosseau A, Makal A, Woźniak K. J. Org. Chem. 2015; 80:2573-2581. [PubMed: 25642784] (c) Vasseur A, Laugel C, Harakat D, Muzart J, Le Bras J. Eur. J. Org. Chem. 2015; 5:944-948.

11.

For other applications of DAF in Pd-catalyzed oxidation reactions, see: Sharma A, Hartwig JF. J. Am. Chem. Soc. 2013; 135:17983-17989. [PubMed: 24156776] Malik HA, Taylor BLH, Kerrigan JR, Grob JE, Houk KN, Du Bois J, Hamann LG, Patterson AW. Chem. Sci. 2014; 5:2353-2361.

12. (a) Li B, Li B, Zhu X, Zhang Y. Inorg. Chem. Commun. 2003; 6:1304-1306.(b) Siemeling U, Scheppelmann I, Neumann B, Stammler H-G, Schoeller WW. Organometallics. 2004; 23:626-628. (c) Yang H-J, Kou H-Z, Gao F, Cui A-L, Wang R-J. Acta Crystallogr., Sec. E: Struct. Rep. Online. 2004; 60:m611-m613.(d) Zhang R-L, Zhao J-S, Yang S-Y, Ng SW. Acta Crystallogr., Sec. E: Struct. Rep. Online. 2004; 60:m262-m263.(e) Tian A, Han Z, Peng J, Ying J, Sha J, Dong B, Zhai J, Liu H. Inorg. Chim. Acta. 2008; 361:1332-1338.(f) Feng X-L, Zhang Y-P. Acta Crystallogr., Sec. E: Struct. Rep. Online. 2011; 67:m1171.

13. Klein RA, Witte P, van Belzen R, Fraanje J, Goubitz K, Numan M, Schenk H, Ernsting JM, Elsevier CJ. Eur. J. Inorg. Chem. 1998; 3:319-330.

14.

For numerous other examples, see the following "perspective" article and references cited therein:

Annibale VT, Song D. Dalton Trans. 2016; 45:32-49. [PubMed: 26621438]

15 .

See ref. 7 and the following: Xu Z-G, Liu H-Y, Zhan Q-G, Chen J, Xu M-J. Acta Crystallogr., Sec. E. 2009; 65:m1166.

16. White PB, Jaworski JN, Zhu GH, Stahl SS. submitted for publication.

17. (a) Milani B, Alessio E, Mestroni G, Sommazzi A, Garbassi F, Zangrando E, Bresciani-Pahor N, Randaccio L. J. Chem. Soc,. Dalton Trans. 1994; 13:1903-1911.(b) Ragaini F, Gasperini M, Cenini S, Arnera L, Caselli A, Macchi P, Casati N. Chem. Eur. J. 2009; 15:8064-8077. [PubMed: 19274690] (c) Bercaw JE, Day MW, Golisz SR, Hazari N, Henling LM, Labinger JA, Schofer SJ, Virgil S. Organometallics. 2009; 28:5017-5024.(d) Ye Y, Ball ND, Kampf JW, Sanford MS. J. Am. Chem. Soc. 2010; 132:14682-14687. [PubMed: 20866077]

18.

TOCSY $=$ Total Correlation Spectroscopy. This technique uses scalar coupling to transfer magnetization from one nuclei to another. The extent of transfer depends on the mixing time, with longer mixing times unveiling more of the coupling network, and will proceed until a quaternary center or non-protonated heteroatom is encountered.

19.

ROESY = Rotating-frame Nuclear Overhauser Effect Spectroscopy. This technique is similar to NOESY in that it detects through-space interactions between protons. The ROESY experiment locks the selected magnetization along a specific direction in the transverse plane (rotating frame) 
by a high-power spinlock rather than along the z-axis (NOESY). The sign of an ROE is always positive, whereas the sign of an NOE is dependent on the tumbling frequency of the molecule relative to the static magnetic field. At the temperatures used in the experiments in this study, NOE data cannot unambiguously distinguish between through-space interactions and chemical exchange. See the Supporting Information for more details.

20.

$\mathrm{HMBC}=$ Heteronuclear Multiple-Bond Correlation spectroscopy is a long-range scalar coupling experiment that involves polarization transfer from ${ }^{1} \mathrm{H}$ to X-nuclei that are typically 2 or 3 bonds away. It is often used to resolve the chemical shift of insensitive nuclei in structure determination studies.

21.

This upfield shift in the ${ }^{15} \mathrm{~N}$ resonance when $\mathrm{Pd}^{\mathrm{II}}$ is coordinated is due to the occupation of the lonepair in bonding. The ${ }^{15} \mathrm{~N}$ chemical shift is also sensitive to the oxidation state of the metal, the coordination geometry (axial vs equatorial) and the ligand trans to the nitrogen See: Mason J. Chem. Rev. 1981; 81:205-227. Pazderski L, Szłyk E, Sitkowski J, Kamieński B, Kozerski L, Toušek J, Marek R. Magn. Reson. Chem. 2006; 44:163-170. [PubMed: 16392105]

22.

ROESY experiments aimed at observing an ROE from OAc ${ }^{1}$ or $\mathrm{OAc}^{2}$ to $\mathrm{OAc}^{3}$ are complicated by chemical exchange that occurs among the acetate resonances (see Figure S5).

23.

The chemical shifts of the acetate $-\mathrm{CH}_{3}$ groups seem to follow some general trends that are helpful to guide structural assignment (cf. Table S1). For example, we find that the cis acetates in $\mathrm{Pd}\left(\kappa^{2}-\mathrm{N}\right.$ $\mathrm{N})(\mathrm{OAc})_{2}$ complexes typically have $-\mathrm{CH}_{3}{ }^{1} \mathrm{H}$ resonances $>2.1 \mathrm{ppm}$, while the trans acetates in $\mathrm{PdL}_{2}(\mathrm{OAc})_{2}$ complexes typically have ${ }^{1} \mathrm{H}$ resonances $<1.9 \mathrm{ppm}$. The bridging acetates that are present in the Pd dimers observed in this study have chemical shifts fall into a chemical shift region between the cis- and trans- $\kappa^{1}$-acetates (1.9-2.1 ppm).

24.

See Supporting Information for full computational details. Optimization and frequencies calculations were performed with rB3LYP/6-31+G* for all non-Pd atoms and the Stuttgart 1997 basis set/ECP was used for Pd. PCM solvation calculations were performed with $\mathrm{CHCl}_{3}$ solvent parameters and at a higher basis set $\left(6-311+\mathrm{G}^{* *}\right)$ for all non-Pd atoms.

25 .

The experimental barrier was calculated from observing the lineshape of the acetate peaks for $\mathbf{D}$ and $\mathbf{E}$ variable-temperature NMR experiments (Figure S11-S12).

26.

The chemical shift of the acetate $-\mathrm{CH}_{3}$ groups of $\mathbf{C}$ at $1.85 \mathrm{ppm}$ is significantly more downfield than the acetate resonances associated with $\mathbf{D}(1.66 \mathrm{ppm})$ and $\mathbf{E}(1.52 \mathrm{ppm})$. These relative chemical shifts align with the general trends that we observe for chemical shifts of cis- versus trans-acetates ligands in other complexes (cf. ref. 23).

27.

A similar structure was obtained with pentafluorobenzoate ligands. See Supporting Information for Xray crystallographic data for this species (Structure M, S52).

28. (a) Nelyubina YV, Korlyukov AA, Lyssenko KA. 1,10-Phenanthroline. Mendeleev Commun. 2014; 24:286-289.(b) Amarante TR, Figueiredo S, Lopes AD, Gonçalves IS, Paz FAA. 4,4'-Di-tertbutyl-2,2'-bipyridine. Acta Cryst. 2009; E65:o2047.(c) Kavitha SJ, Panchanatheswaran K, Low 
JK, Glidewell C. 2,2'-bipyridine. Acta Crystallogr., Sect. C: Cryst. Struct. Commun. 2005;

61:o473.(d) Fun H-K, Sivakumar K, Zhu D-R, You X-Z. DAF. Acta Cryst. 1995; C51:2076-2078. 29.

See Supporting Information for crystal structure data.

30. (a) Klein A, Lepski R. Z. Anorg. Allg. Chem. 2009; 635:878-884.(b) Fornies J, Navarro R, Sicilia V, Tomas M. Inorg. Chem. 1993; 32(17):3675-3681.

31. (a) Wilke G, Schott H, Heimbach P. Angew. Chem. Int. Ed. 1967; 6:92-93.(b) Konnick MM, Guzei IA, Stahl SS. J. Am. Chem. Soc. 2004; 126:10212-10213. [PubMed: 15315411] (c) Konnick MM, Stahl SS. J. Am. Chem. Soc. 2008; 130:5753-5762. [PubMed: 18393426] (d) Konnick MM,

Decharin N, Popp BV, Stahl SS. Chem. Sci. 2011; 2:326-330.

32. Steinhoff BA, Stahl SS. J. Am. Chem. Soc. 2006; 128:4348-4355. [PubMed: 16569011]

33.

See refs. 2f, 3c and the following for examples: Steinhoff BA, Stahl SS. Org. Lett. 2002; 4:4179-4181.

[PubMed: 12423116] Schultz MJ, Park CC, Sigman MS. Chem. Commun. 2002:3034-3035. Ye

XA, Liu GS, Popp BV, Stahl SS. J. Org. Chem. 2011; 76:1031-1044. [PubMed: 21250706]

34. White PB, Stahl SS. J. Am. Chem. Soc. 2011; 133:18594-18597. [PubMed: 22007610]

35. (a) Lin B-L, Labinger JA, Bercaw JE. Can. J. Chem. 2009; 87:264-271.(b) Guo HJ, Chen Z, Mei F, Zhu D, Xiong H, Yin G. Chem.-Asian J. 2013; 8:888-891. [PubMed: 23401395]

36.

We thank Dr. Jay A. Labinger (Caltech) for drawing our attention to this relationship between DAF/ $\mathrm{Pd}(\mathrm{OAc})_{2}$ and the bpm- $\left[\mathrm{Pd}(\mathrm{OAc})_{2}\right]_{2}$ catalyst system.

37.

For related observations made recently in the study of stoichiometric reactions of $\mathrm{Pd}(\mathrm{bpym}) \mathrm{Ar}_{2}$, see:

Liberman-Martin AL, Levine DS, Liu W, Bergman RG, Tilley TD. Organometallics. 2016 T. D. 

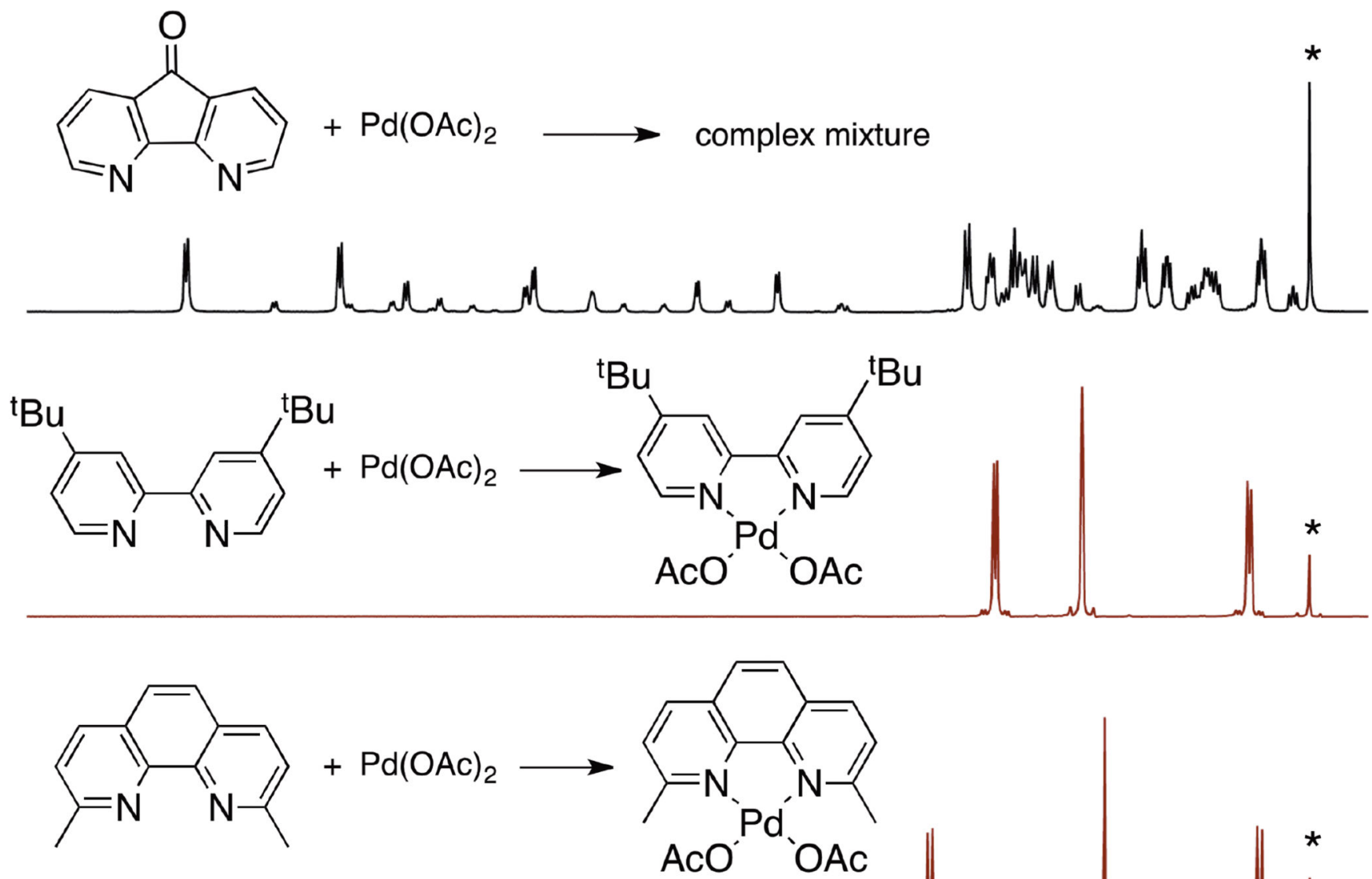

$\begin{array}{lllll}11.0 & 10.5 & 10.0 & 9.5 & 1 \mathrm{H}(\mathrm{ppm})\end{array}$

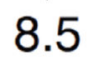

8.0

7.5

Figure 1.

${ }^{1} \mathrm{H}$ NMR spectra of 1:1 solutions of $\mathrm{Pd}(\mathrm{OAc})_{2}$ and three different bidentate nitrogen ligands highlighting the unusual complexity of the $\mathrm{DAF} / \mathrm{Pd}(\mathrm{OAc})_{2}$ mixture. $\left[\mathrm{Pd}(\mathrm{OAc})_{2}\right]=40 \mathrm{mM}$, [Ligand] $=40 \mathrm{mM}, \mathrm{T}=-45^{\circ} \mathrm{C}$ (top) and $24{ }^{\circ} \mathrm{C}$ (middle and bottom), solvent $=\mathrm{CDCl}_{3}(0.5$ $\mathrm{mL})$; The * designates the $\mathrm{CHCl}_{3}$ solvent peak. 
A) NMR Titration of DAF with $\mathrm{Pd}(\mathrm{OAc})_{2}$
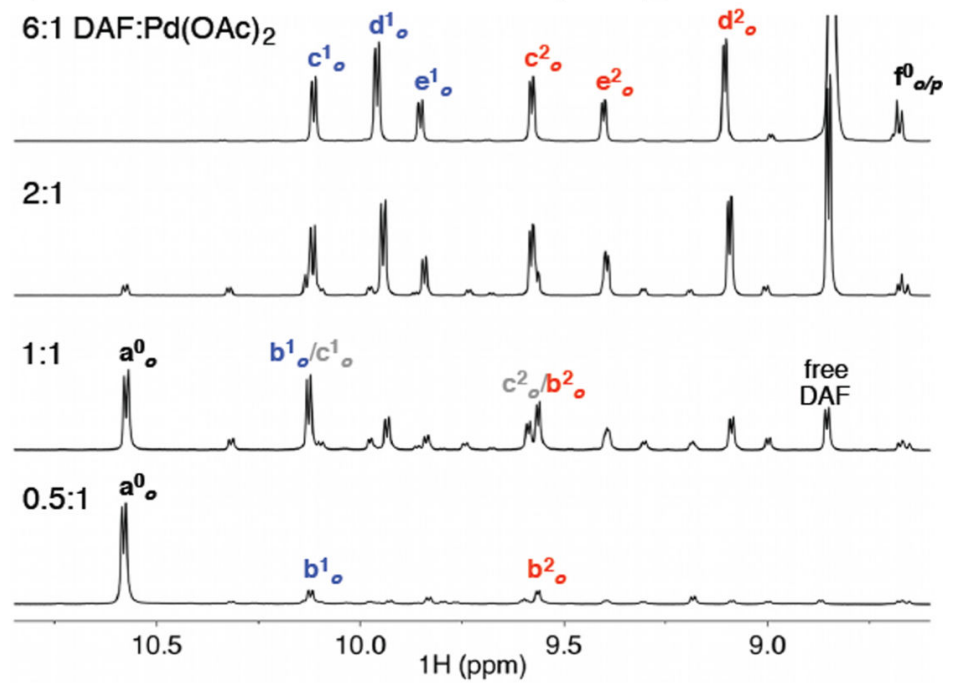

B) Nomenclature for Spectral Assignment
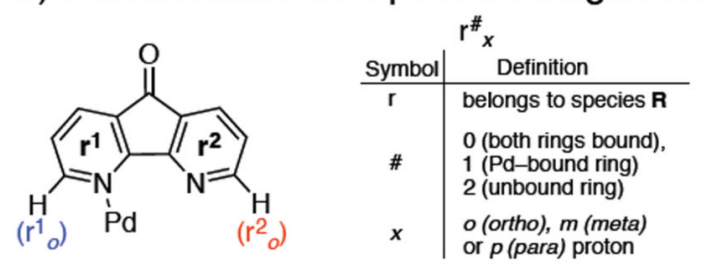

Species composition:

$$
\begin{aligned}
& A=a^{0} \\
& B=b^{1}+b^{2} \\
& C=c^{1}+c^{2} \\
& D=d^{1}+d^{2} \\
& E=e^{1}+e^{2} \\
& F=f^{0}
\end{aligned}
$$

\section{C) [Species] vs Equivalents DAF}

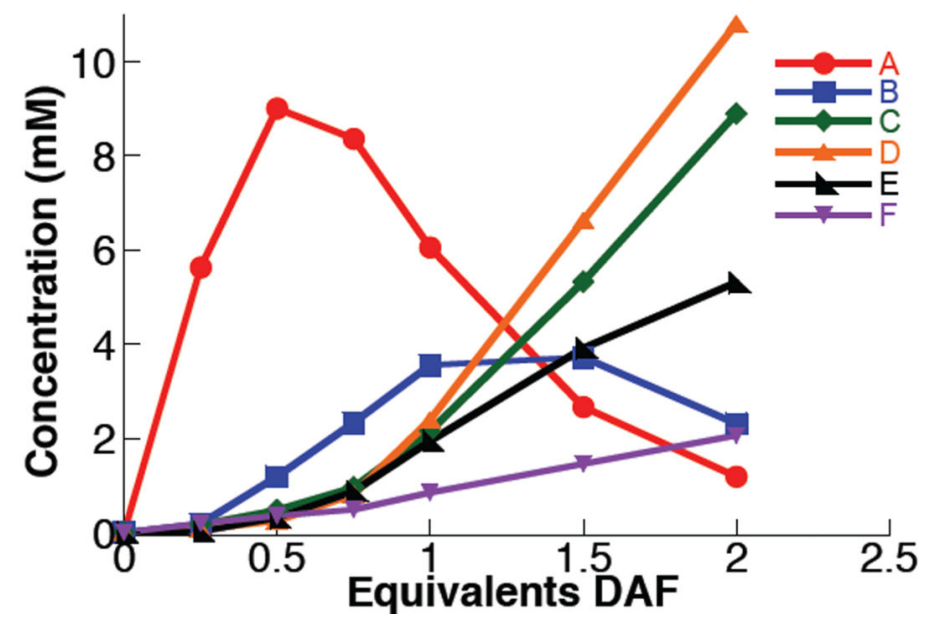

Figure 2.

${ }^{1} \mathrm{H}$ NMR spectra obtained from the titration of DAF with $\mathrm{Pd}(\mathrm{OAc})_{2}$ at $-45^{\circ} \mathrm{C}(\mathrm{A})$. Description of the nomenclature used to assign resonances in the NMR spectra (B). Speciation plot associated with the six $\mathrm{DAF} / \mathrm{Pd}(\mathrm{OAc})_{2}$ complexes identified in the titration experiments $(\mathrm{C})$. 

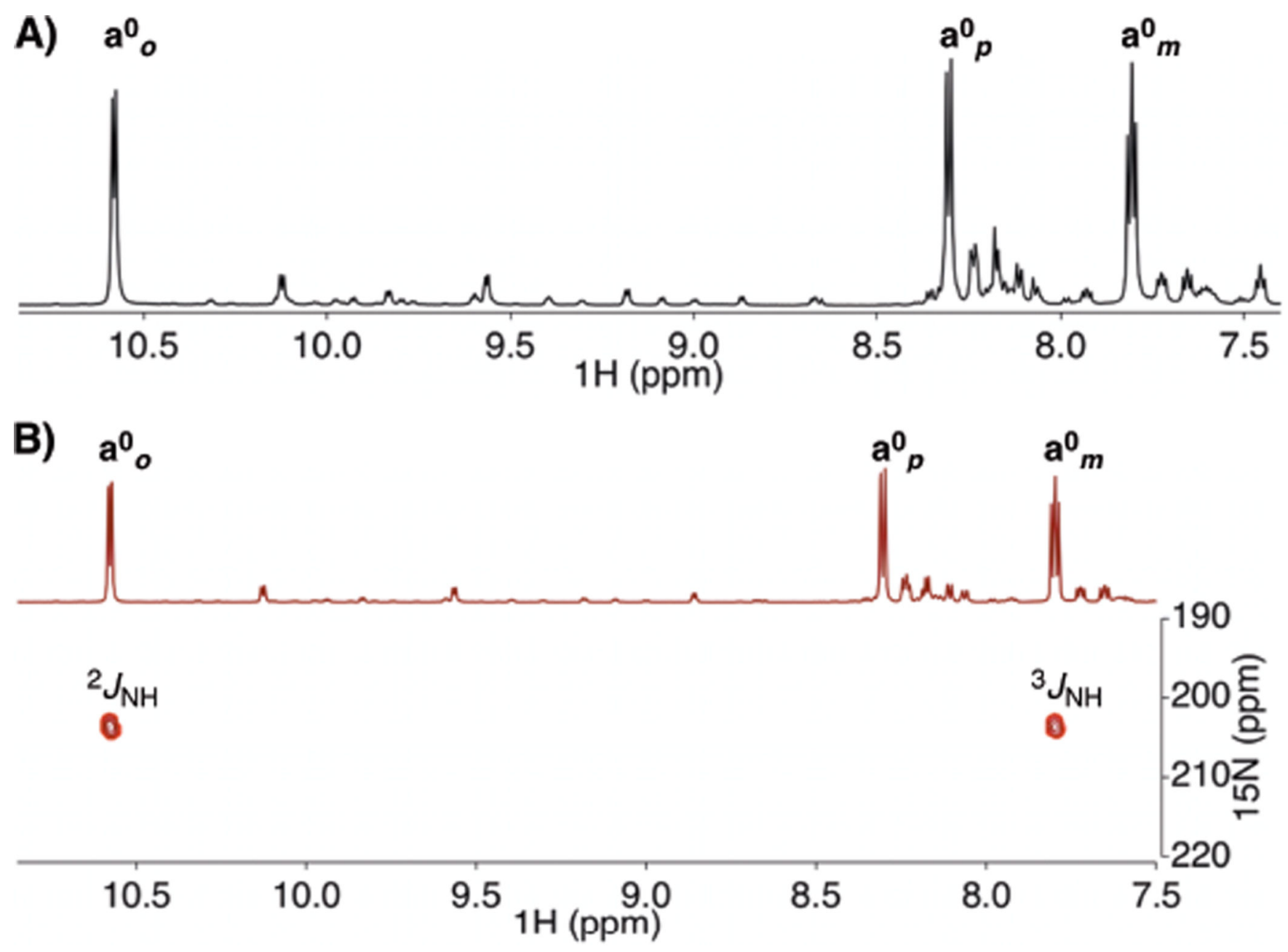

Figure 3.

$1 \mathrm{D}{ }^{1} \mathrm{H}(\mathrm{A})$ and ${ }^{1} \mathrm{H}_{-}{ }^{15} \mathrm{~N}$ HMBC spectra $(\mathrm{B})$ of a solution of $\mathrm{Pd}(\mathrm{OAc})_{2}$ and 0.5 equiv of DAF in $\mathrm{CDCl}_{3}$, focusing on the aromatic spectral region. Cross-peaks for both 2- and 3-bond $\mathrm{N}-$ $\mathrm{H}$ coupling are observed. $\left[\mathrm{Pd}(\mathrm{OAc})_{2}\right]=40 \mathrm{mM},[\mathrm{DAF}]=20 \mathrm{mM}, \mathrm{T}=-45^{\circ} \mathrm{C}$, solvent $=$ $\mathrm{CDCl}_{3}(0.5 \mathrm{~mL}) .{ }^{1} \mathrm{H}_{-}{ }^{15} \mathrm{~N}$ HMBC: dof $=250 \mathrm{ppm}, \mathrm{sw} 1=250 \mathrm{ppm}, \mathrm{nt}=16, \mathrm{~d} 1=4, \mathrm{ni}=256$. 

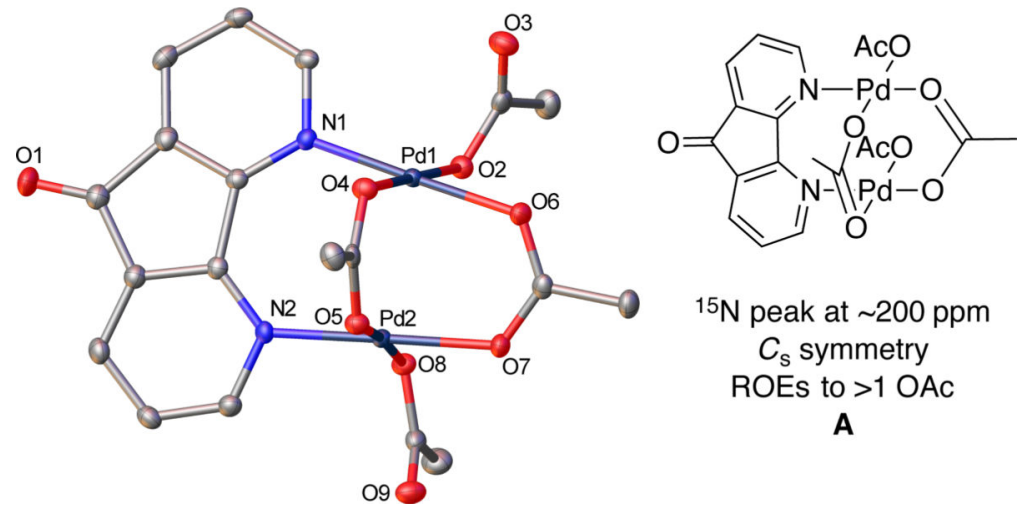

${ }^{15} \mathrm{~N}$ peak at $\sim 200 \mathrm{ppm}$

$C_{\mathrm{s}}$ symmetry ROEs to $>1$ OAC

A

Figure 4.

X-ray crystal structure of $\mathbf{A}$ and summary of NMR spectroscopic data supporting this structure in solution. The crystal structure is drawn with $50 \%$ probability ellipsoids and all $\mathrm{H}$ atoms are omitted for clarity. See Supporting Information for details. 

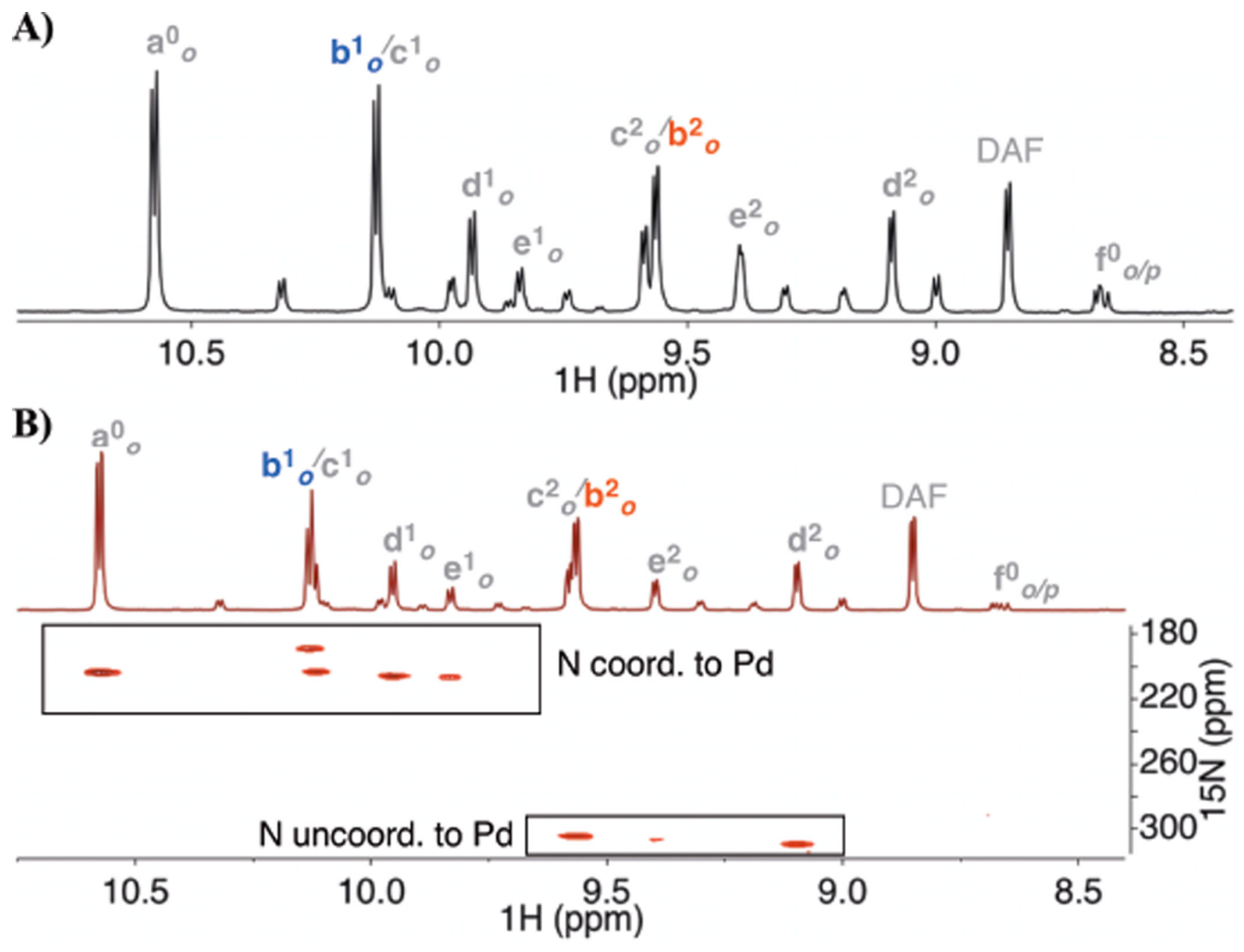

Figure 5.

1D ${ }^{1} \mathrm{H}(\mathrm{A})$ and ${ }^{1} \mathrm{H}-{ }^{15} \mathrm{~N}$ HMBC spectra (B) of a solution of $\mathrm{Pd}(\mathrm{OAc})_{2}$ and 1 equiv of DAF in $\mathrm{CDCl}_{3}$, focusing on the aromatic spectral region. The resonances appearing at $<220 \mathrm{ppm}$ correspond to coordinated nitrogen atoms of DAF ligands, while those appearing at $>300$ ppm correspond to unbound nitrogen atoms. $\left[\mathrm{Pd}(\mathrm{OAc})_{2}\right]=40 \mathrm{mM},[\mathrm{DAF}]=40 \mathrm{mM}, \mathrm{T}=$ $-45^{\circ} \mathrm{C}$, solvent $=\mathrm{CDCl}_{3}(0.5 \mathrm{~mL}) .{ }^{1} \mathrm{H}^{-15} \mathrm{~N} \mathrm{HMBC}:$ dof $=250 \mathrm{ppm}, \mathrm{sw} 1=250 \mathrm{ppm}, \mathrm{nt}=$ $40, \mathrm{~d} 1=6 \mathrm{~s}, \mathrm{ni}=256$. 

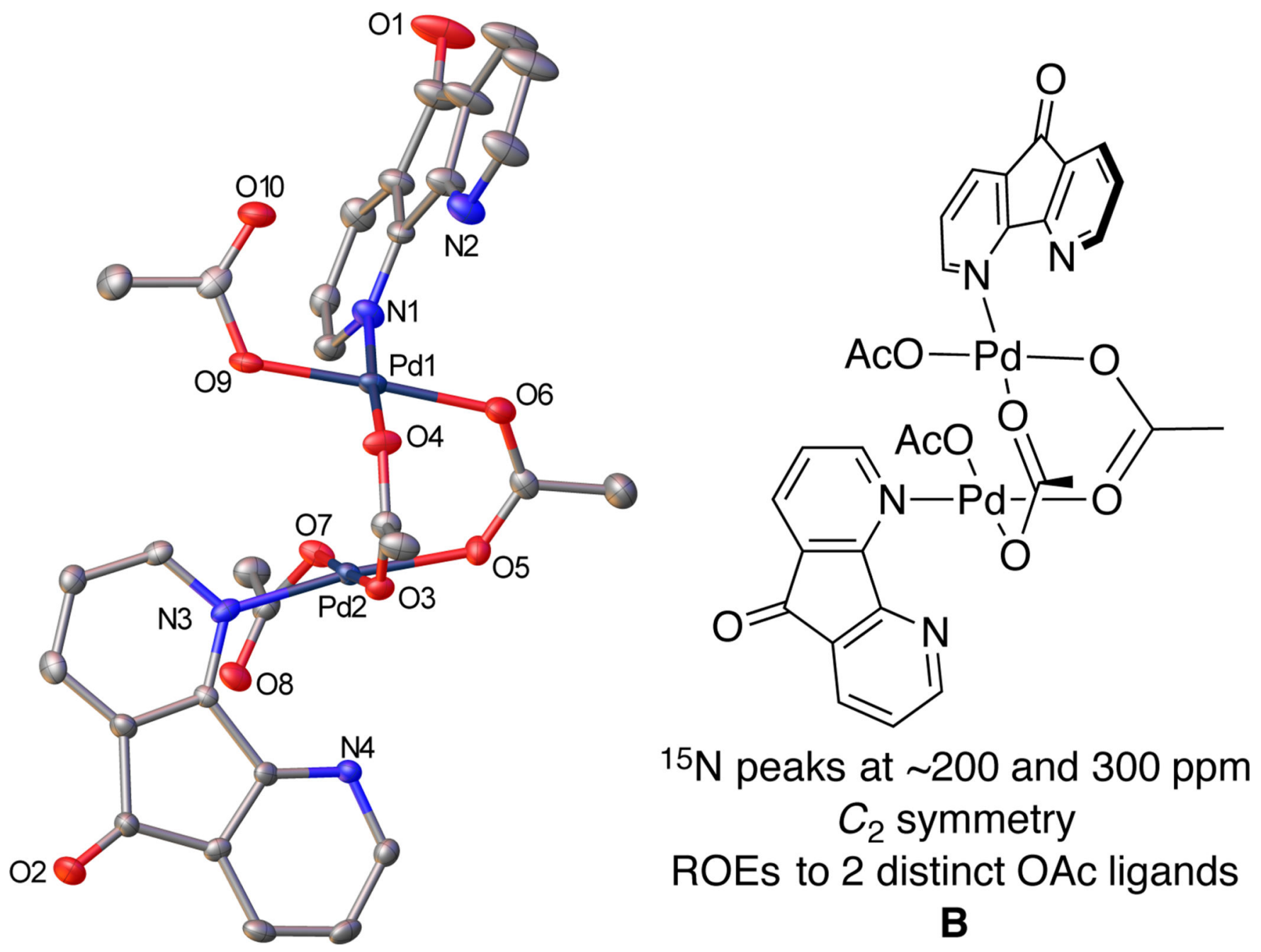

Figure 6.

X-ray crystal structure of $\mathbf{B}$ and summary of NMR spectroscopic data supporting this structure in solution. The crystal structure is drawn with $50 \%$ probability ellipsoids and all $\mathrm{H}$ atoms are omitted for clarity. See Supporting Information for details. 


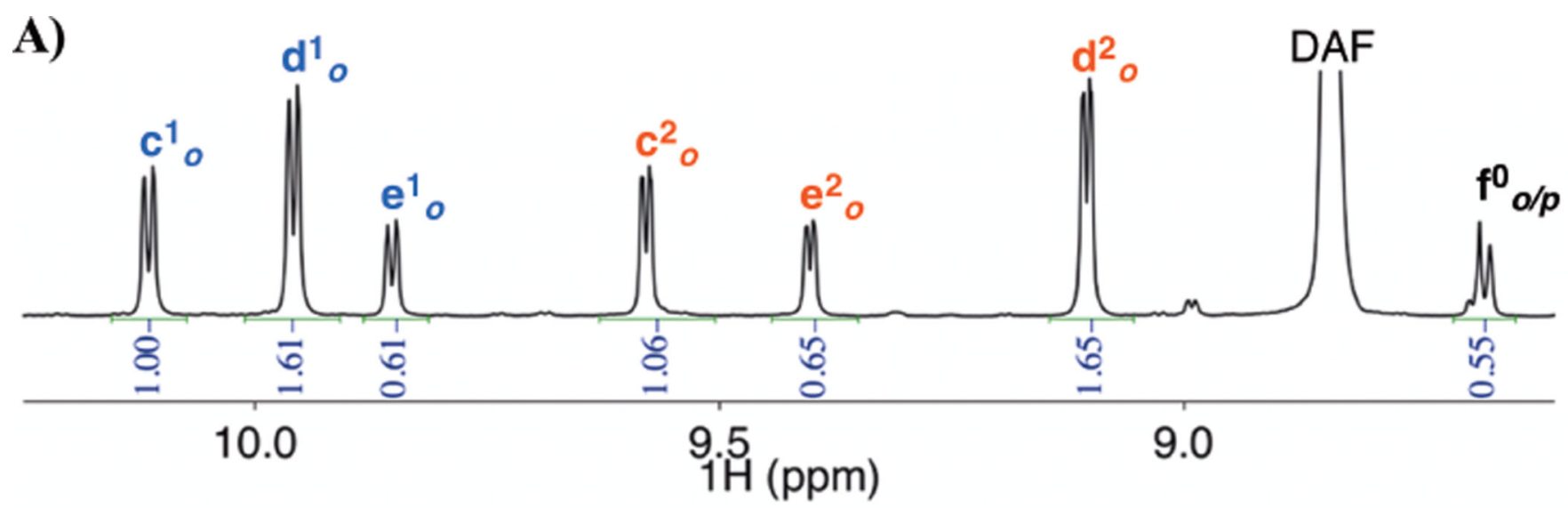

B)
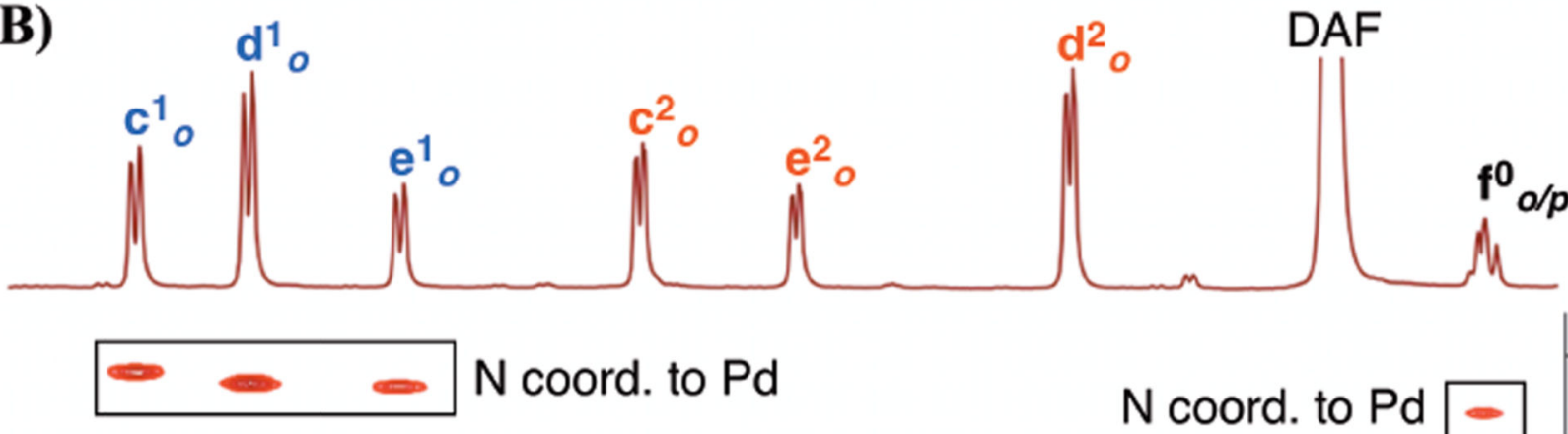

$\mathrm{N}$ coord. to $\mathrm{Pd}=$

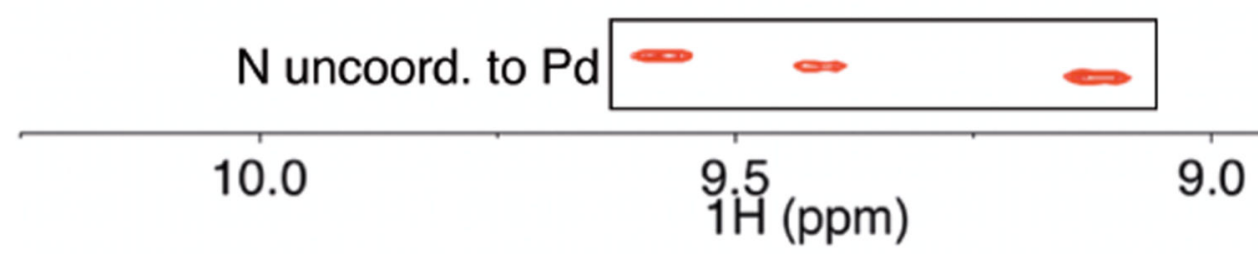

free DAF

Figure 7.

1D ${ }^{1} \mathrm{H}$ (A) and ${ }^{1} \mathrm{H}_{-}{ }^{15} \mathrm{~N}$ HMBC spectra (B) of a solution of $\mathrm{Pd}(\mathrm{OAc})_{2}$ and 6 equiv of DAF in

$\mathrm{CDCl}_{3}$, focusing on the aromatic spectral region. The resonances appearing at $<220 \mathrm{ppm}$ correspond to coordinated nitrogen atoms of DAF ligands, while those appearing at $>300$ ppm correspond to unbound nitrogen atoms. $\left[\mathrm{Pd}(\mathrm{OAc})_{2}\right]=40 \mathrm{mM},[\mathrm{DAF}]=240 \mathrm{mM}, \mathrm{T}=$ $-45^{\circ} \mathrm{C}$, solvent $=\mathrm{CDCl}_{3}(0.5 \mathrm{~mL}) .{ }^{1} \mathrm{H}_{-}{ }^{15} \mathrm{~N}$ HMBC: $\mathrm{dof}=250 \mathrm{ppm}, \mathrm{sw} 1=250 \mathrm{ppm}, \mathrm{nt}=$ $32, \mathrm{~d} 1=4 \mathrm{~s}, \mathrm{ni}=256$. 

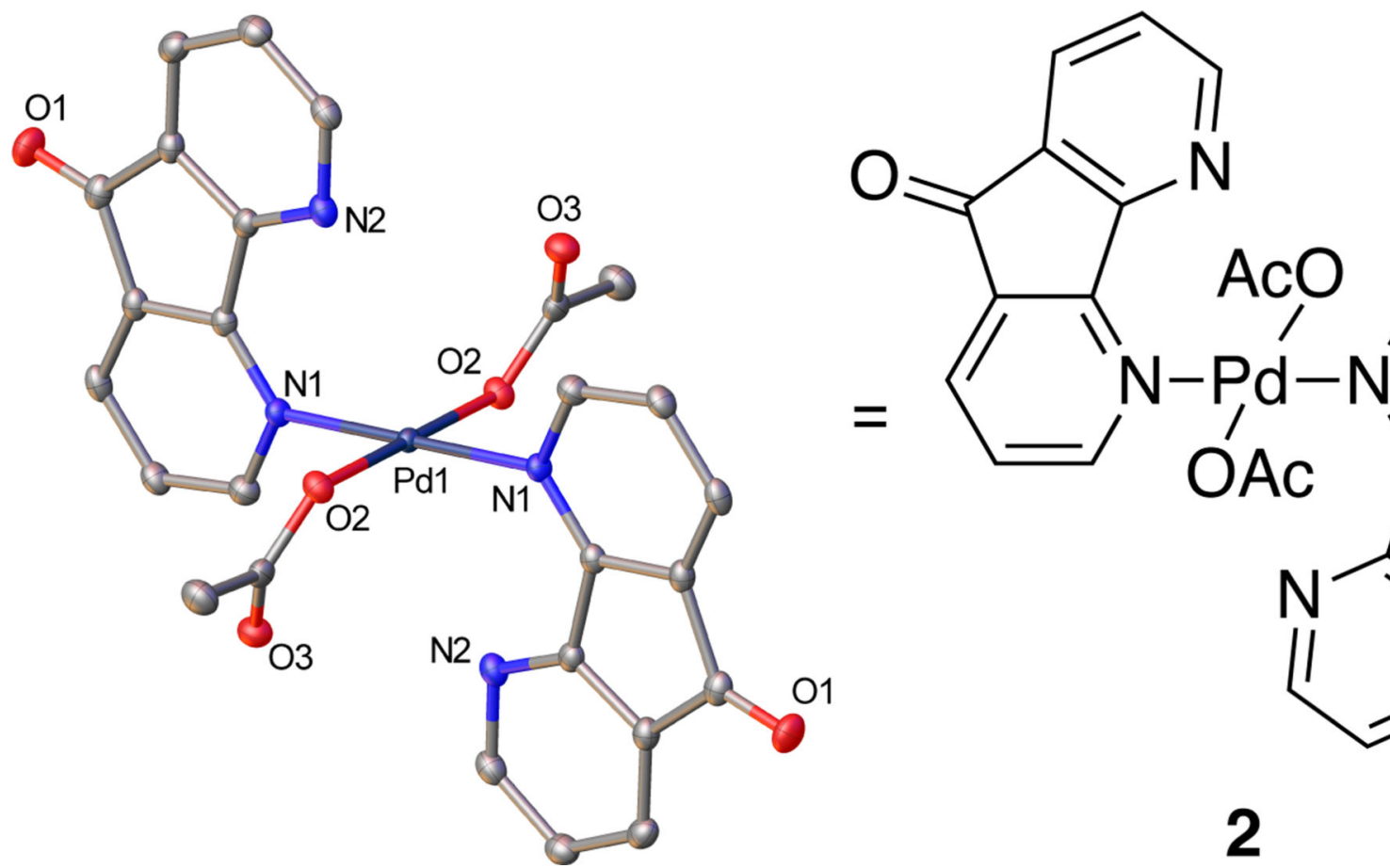

Figure 8.

X-ray crystal structure of trans/anti-Pd( $\left(\kappa^{1}-\mathrm{DAF}\right)_{2}(\mathrm{OAc})_{2} \mathbf{2}$, species $\mathbf{E}$. The crystal structure is drawn with $50 \%$ probability ellipsoids and all $\mathrm{H}$ atoms are omitted for clarity. See Supporting Information for details. 


\section{A) NMR Titration of $\mathrm{Me}_{2} \mathrm{DAF}$ with $\mathrm{Pd}(\mathrm{OAc})_{2}$}
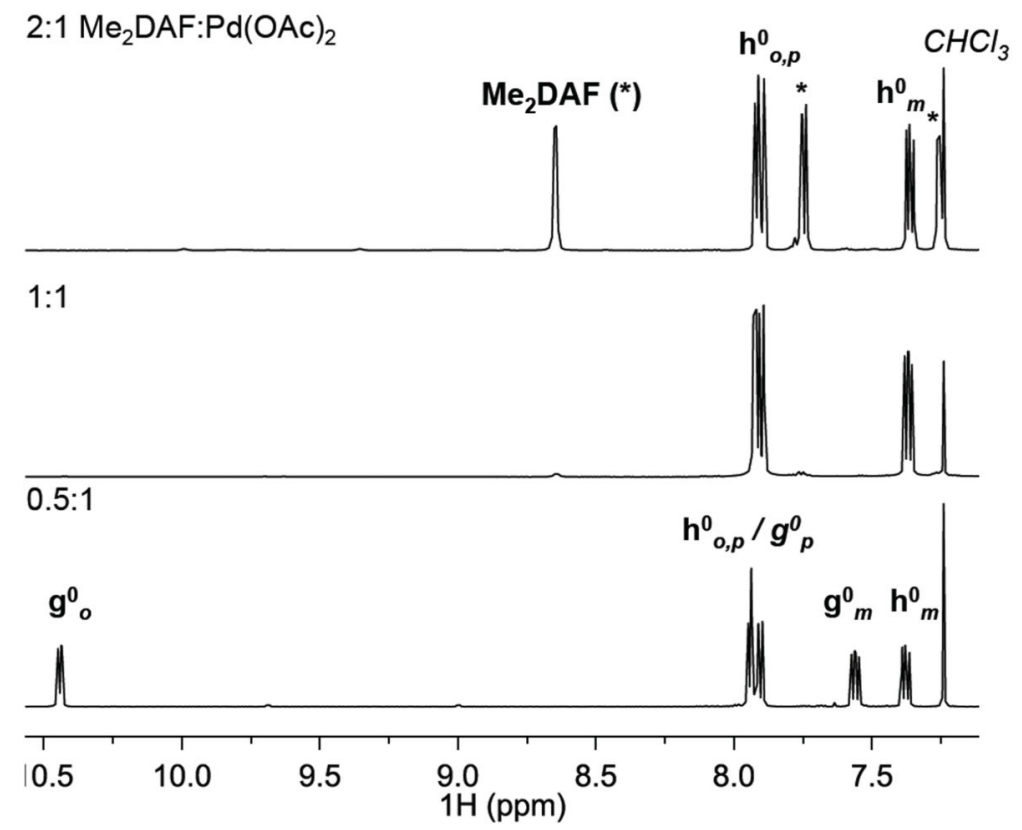

B) [Speciation] vs Equivalents of $\mathrm{Me}_{2} \mathrm{DAF}$

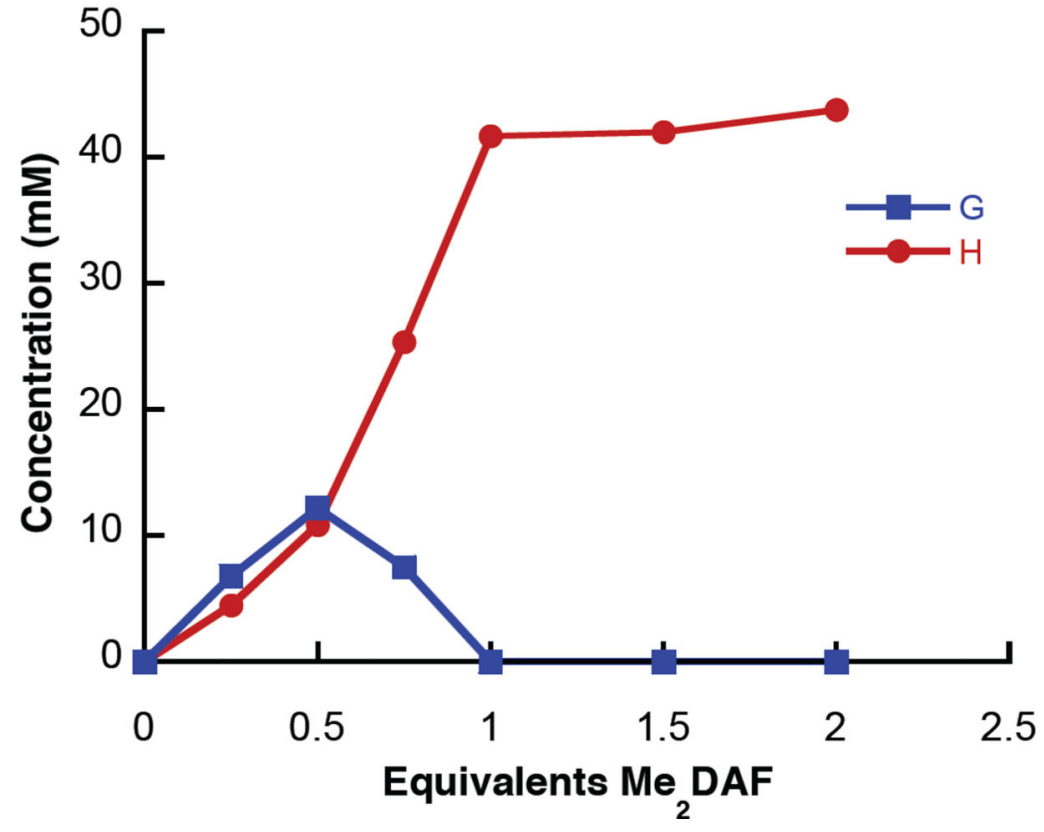

Figure 9.

${ }^{1} \mathrm{H}$ NMR spectra obtained from the titration of $\mathrm{Me}_{2} \mathrm{DAF}$ with $40 \mathrm{mM} \mathrm{Pd}(\mathrm{OAc})_{2}$ at $24{ }^{\circ} \mathrm{C}$ (A). Speciation plot associated with the two $\mathrm{Me}_{2} \mathrm{DAF} / \mathrm{Pd}(\mathrm{OAc})_{2}$ complexes identified in the titration experiments (B). 

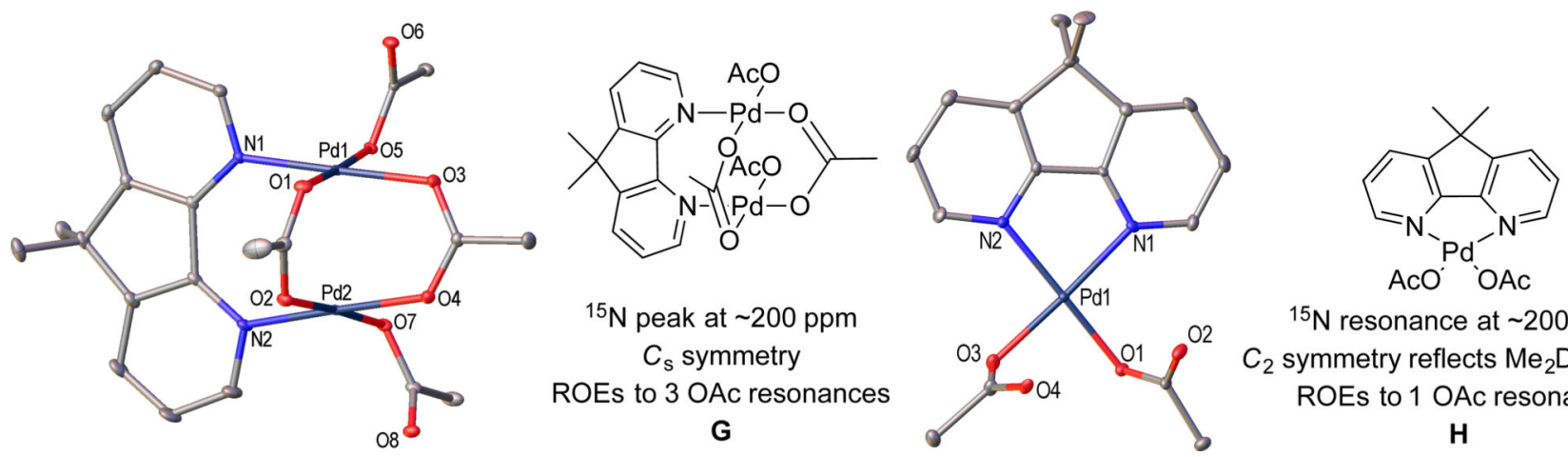

Figure 10.

X-ray crystal structures and summary of NMR spectroscopic data supporting of $\operatorname{Pd}(\mu-$ $\left.\mathrm{Me}_{2} \mathrm{DAF}\right)(\mu-\mathrm{OAc})_{2}\left(\kappa^{1}-\mathrm{OAc}\right)_{2}$ dimer $\mathbf{G}$ (left) and $\mathrm{Pd}\left(\kappa^{2}-\mathrm{Me}_{2} \mathrm{DAF}\right)\left(\kappa^{1}-\mathrm{OAc}\right)_{2}$ monomer $\mathbf{H}$ (right). The crystal structures are drawn with $50 \%$ probability ellipsoids and all $\mathrm{H}$ atoms are omitted for clarity. See Supporting Information for details. 
A) NMR Titration of DAF with $\operatorname{Pd}(T F A)_{2}$

2:1 DAF:Pd(TFA)

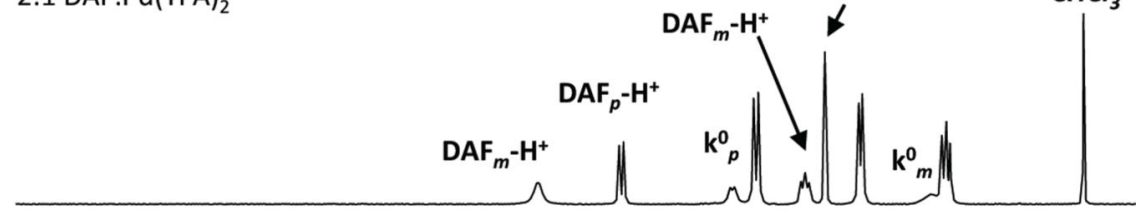

$1: 1$

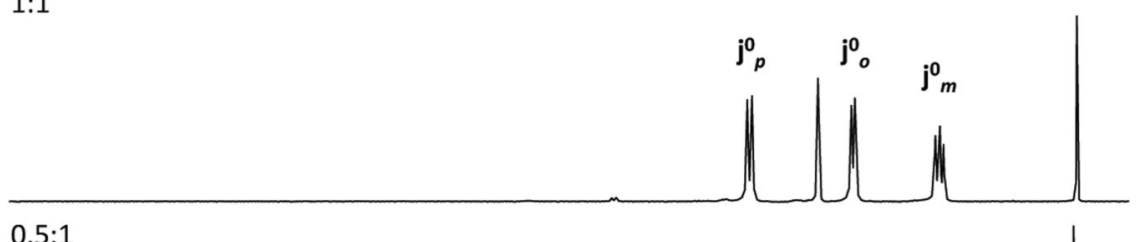

$0.5: 1$
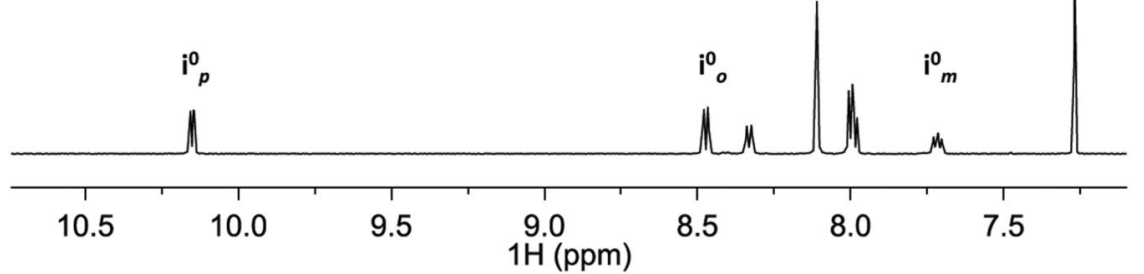

B) [Speciation] vs Equivalents of DAF

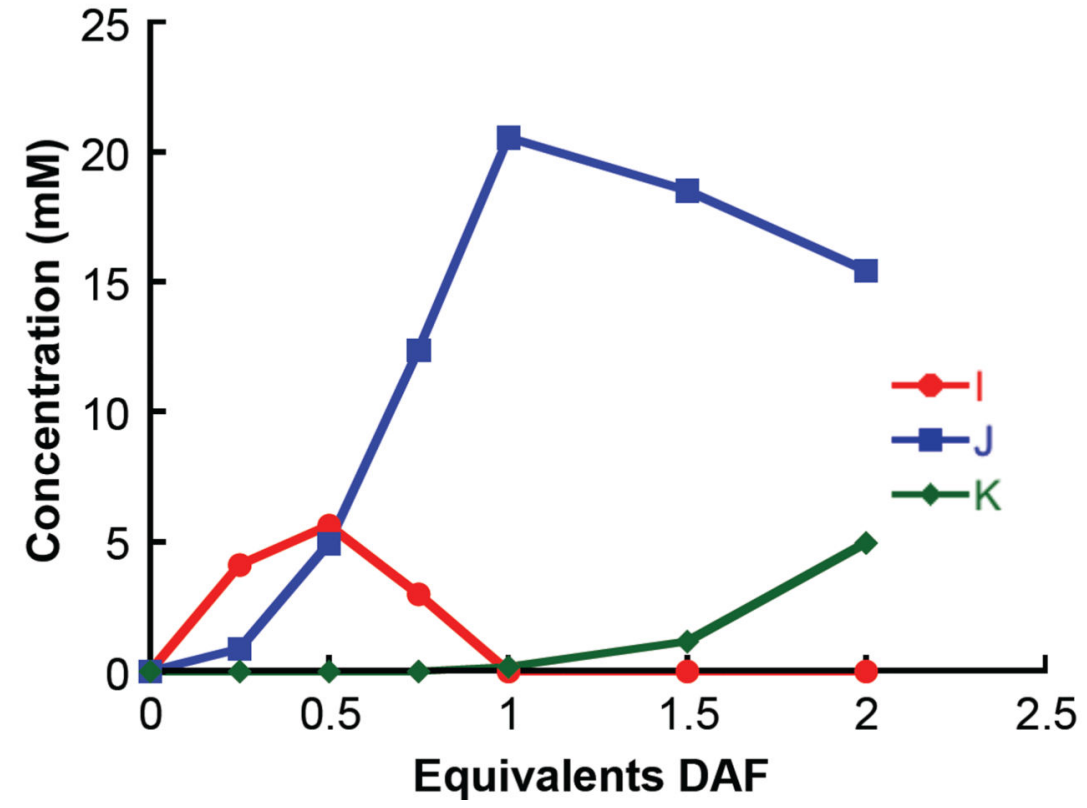

Figure 11.

${ }^{1} \mathrm{H}$ NMR spectra obtained from the titration of DAF with $\left.20 \mathrm{mM} \mathrm{Pd(TFA}\right)_{2}$ in 1:1 TFAH: $\mathrm{CDCl}_{3}$ at $24{ }^{\circ} \mathrm{C}(\mathrm{A})$. Speciation plot associated with the DAF/Pd(TFA) $)_{2}$ complexes identified in the titration experiments (B). 

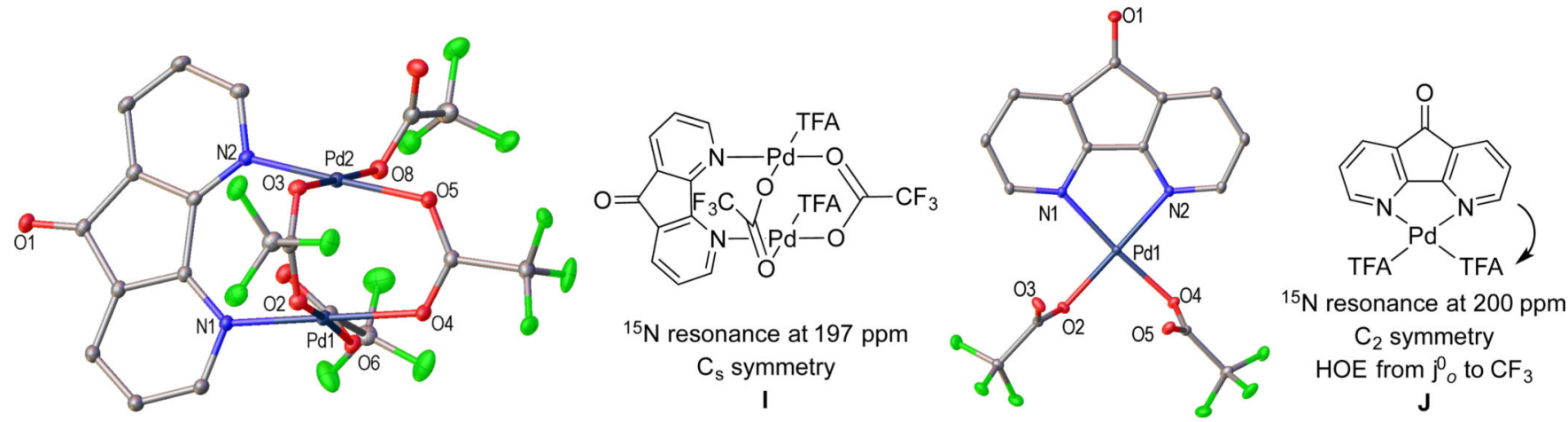

Figure 12.

X-ray crystal structures and summary of NMR spectroscopic data for $\operatorname{Pd}(\mu-\mathrm{DAF})(\mu-$ TFA $)_{2}\left(\kappa^{1}-\text { TFA }\right)_{2}$ dimer I (left) and Pd( $\left(\kappa^{1}-\text { TFA }\right)_{2} \mathrm{~J}$ (right). The crystal structures are drawn with $50 \%$ probability ellipsoids and all $\mathrm{H}$ atoms are omitted for clarity. See Supporting Information for details. 
A) NMR Titration of DAF with Pd(OPiv) ${ }_{2}$
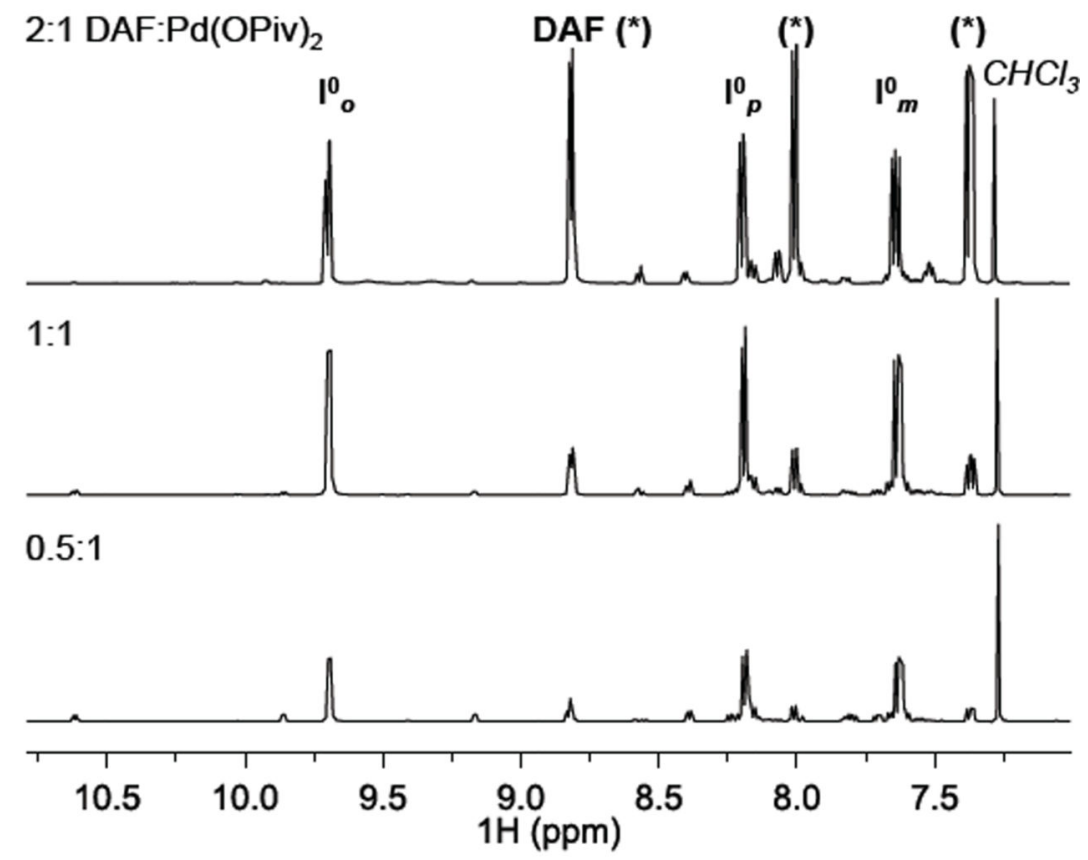

B) [Speciation] vs Equivalents of DAF

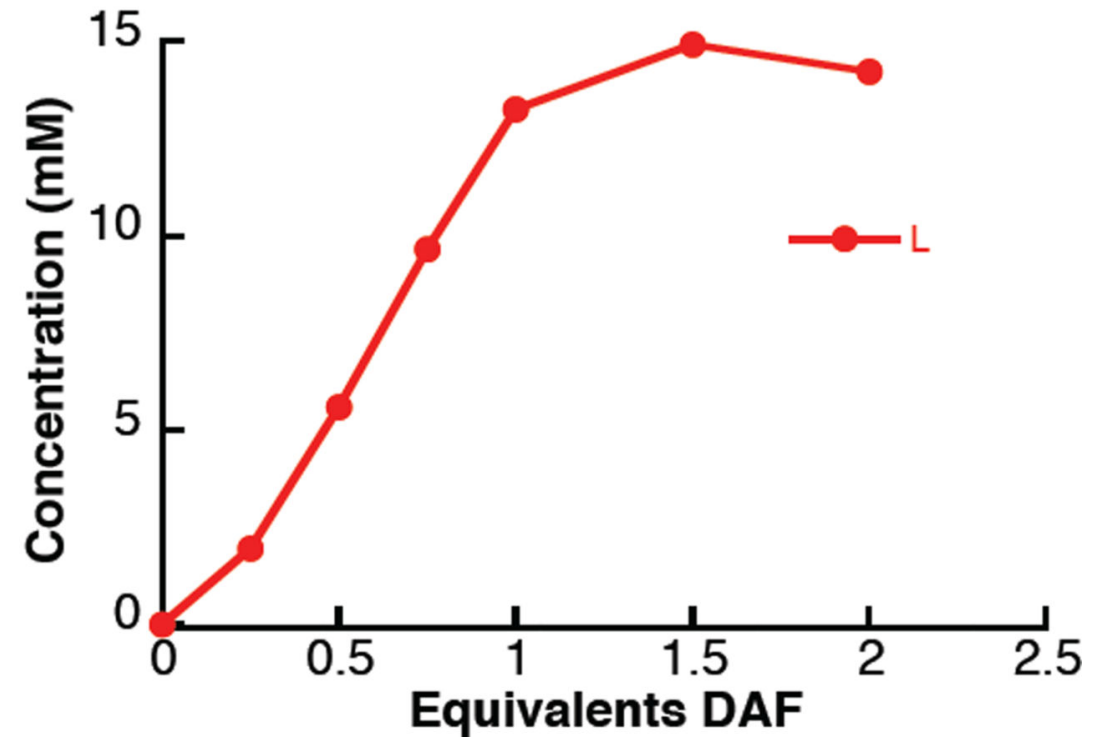

Figure 13.

${ }^{1} \mathrm{H}$ NMR spectra obtained from the titration of DAF with $40 \mathrm{mM} \mathrm{Pd}(\mathrm{OPiv})_{2}$ at $24{ }^{\circ} \mathrm{C}(\mathrm{A})$. Speciation plot associated with the two $\mathrm{DAF} / \mathrm{Pd}(\mathrm{OPiv})_{2}$ complexes identified in the titration experiments (B). 

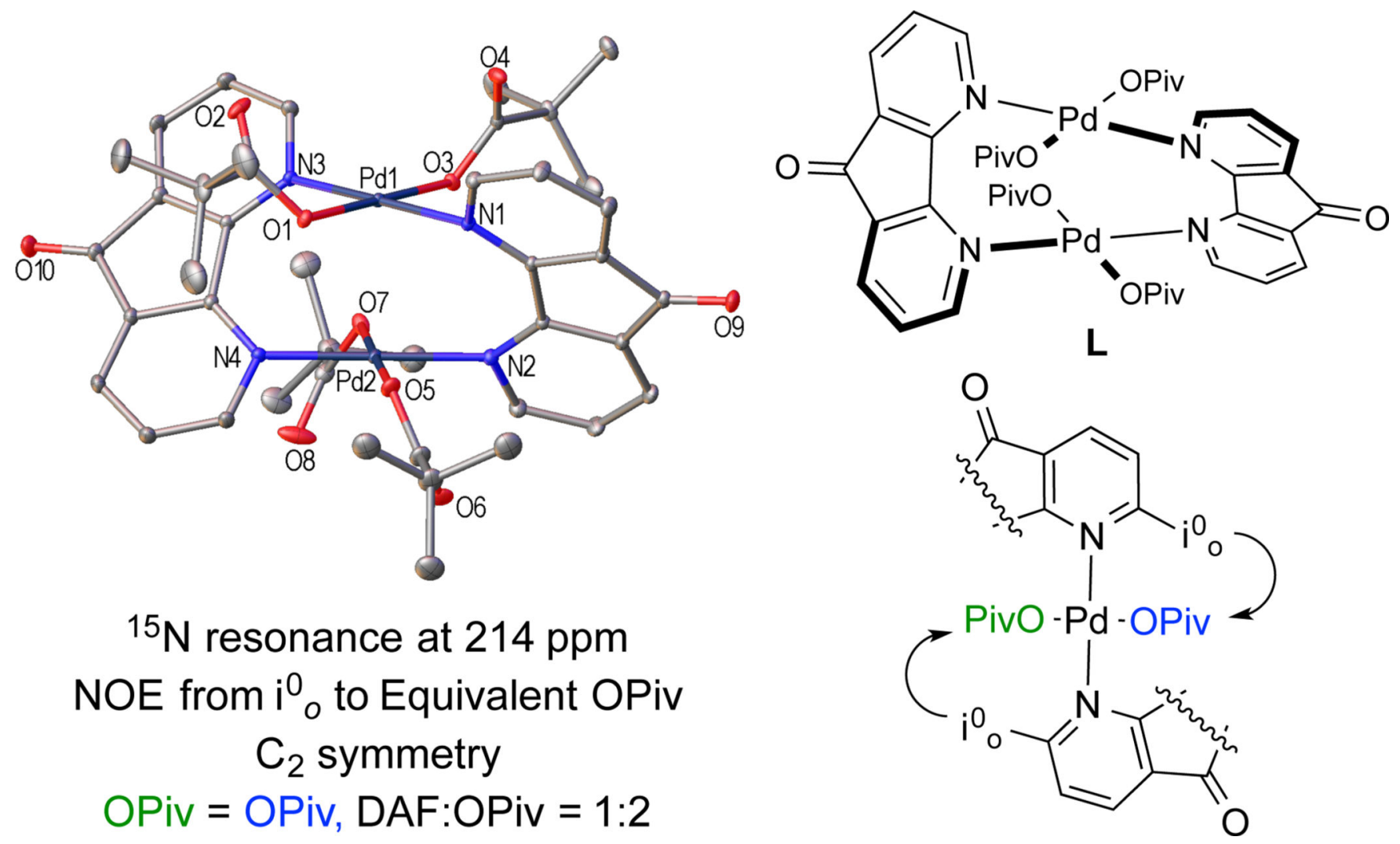

Figure 14.

X-ray crystal structure and summary of NMR spectroscopic data supporting $\operatorname{Pd}_{2}(\mu$ DAF $)_{2}\left(\kappa^{1} \text {-OPiv }\right)_{4}$ dimer $\mathbf{L}$. The crystal structures are drawn with $50 \%$ probability ellipsoids and all $\mathrm{H}$ atoms are omitted for clarity. See Supporting Information for details. 
A.<smiles>CC(=O)OC/C=C/c1ccccc1</smiles>

B.<smiles>[Z]N1[C+]=Cc2ccccc21</smiles>

5 mol\% Pd(OPiv) 2 $\mathrm{Z}=\mathrm{SO}_{2} \mathrm{Ph}$, Piv $\quad 1 \mathrm{~atm} \mathrm{O}_{2}, 120^{\circ} \mathrm{C}, 18 \mathrm{~h}$

$\mathrm{C}_{6} \mathrm{H}_{6} / \mathrm{EtCO}_{2} \mathrm{H}(10: 1)$<smiles>[Z]n1c(-c2ccccc2)cc2ccccc21</smiles>

C.<smiles>CCOC(=O)[C@H]1CCCC1=O</smiles>

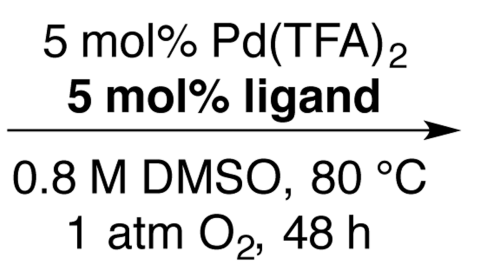<smiles>CCOC(=O)[C@@H]1[C@H]2C=CC(=O)[C@@H]21</smiles>

Reaction<smiles>O=C1c2cccnc2-c2ncccc21</smiles><smiles>c1ccc(-c2ccccn2)nc1</smiles><smiles>c1cnc2c(c1)ccc1cccnc12</smiles>
DAF bpy phen

\begin{tabular}{llll}
\hline A & $81 \%$ & $0 \%$ & $9 \%$ \\
B & $80 \%$ & $0 \%$ & $14 \%$ \\
C & $87 \%$ & $33 \%$ & $36 \%$ \\
\hline
\end{tabular}

Scheme 1.

Representative Pd-Catalyzed Aerobic Oxidation Reactions Promoted by DAF. $7,8,9 \mathrm{a}$ 


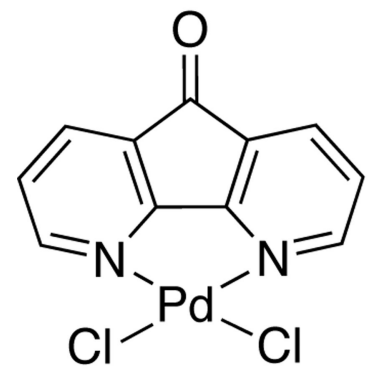

ref 15

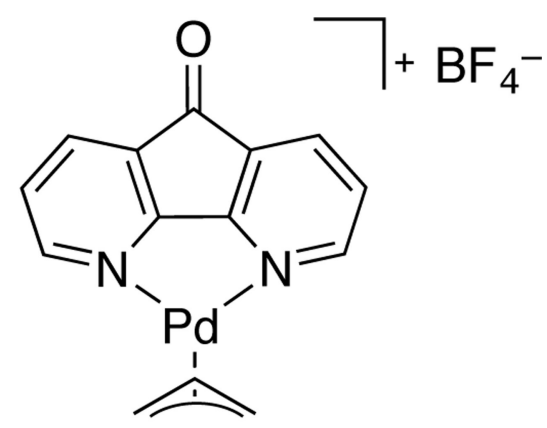

ref 7

Scheme 2.

Previously Characterized DAF/Pd ${ }^{\mathrm{II}}$ Coordination Complexes. 


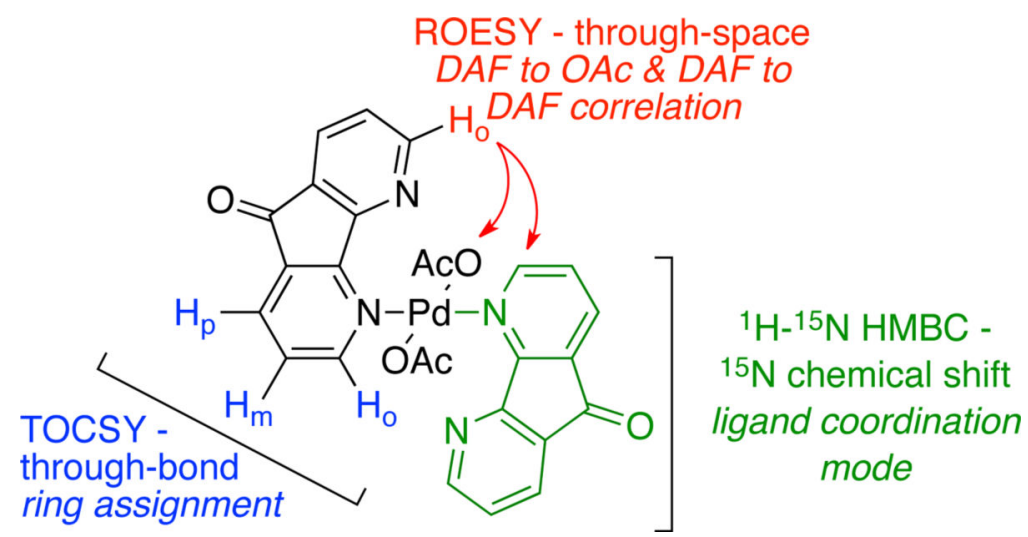

Scheme 3.

Application of NMR Techniques for Structure Assignment. 
${ }^{15} \mathrm{~N}$ Chemical Shift of Free and Coordinated Bpy
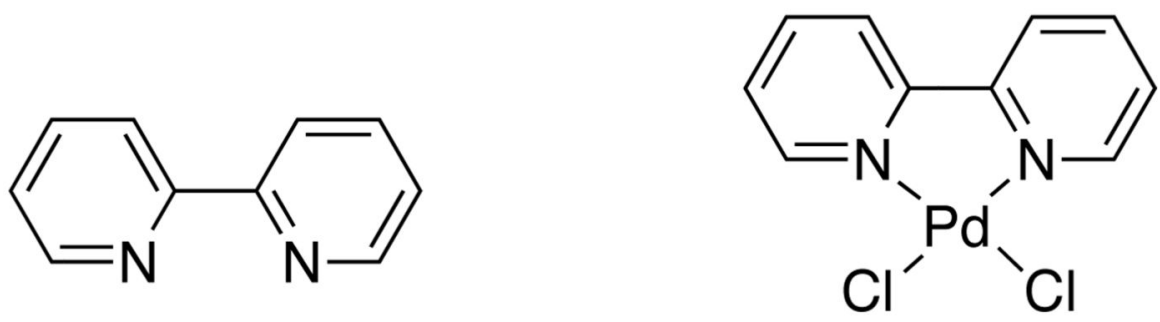

$$
\delta\left({ }^{15} \mathrm{~N}\right)=307 \mathrm{ppm}
$$

$$
\delta\left({ }^{15} \mathrm{~N}\right)=217 \mathrm{ppm}
$$

Application of ${ }^{15} \mathrm{~N}$ Chemical Shift to DAF Coordination

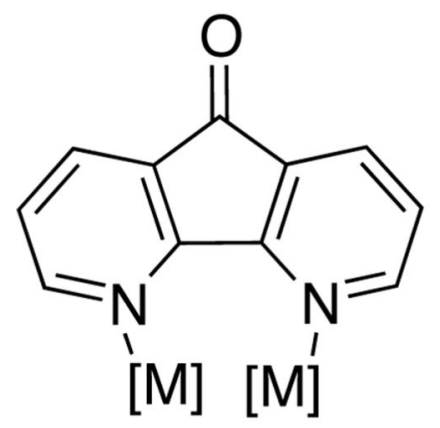

$\delta\left({ }^{15} \mathrm{~N}\right)$ near $200 \mathrm{ppm}$

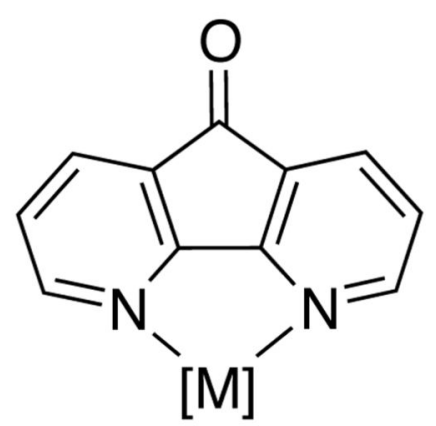

$\delta\left({ }^{15} \mathrm{~N}\right)$ near 200 and $300 \mathrm{ppm}$

Scheme 4.

Effect of Coordination on ${ }^{15} \mathrm{~N}$ Chemical Shift 


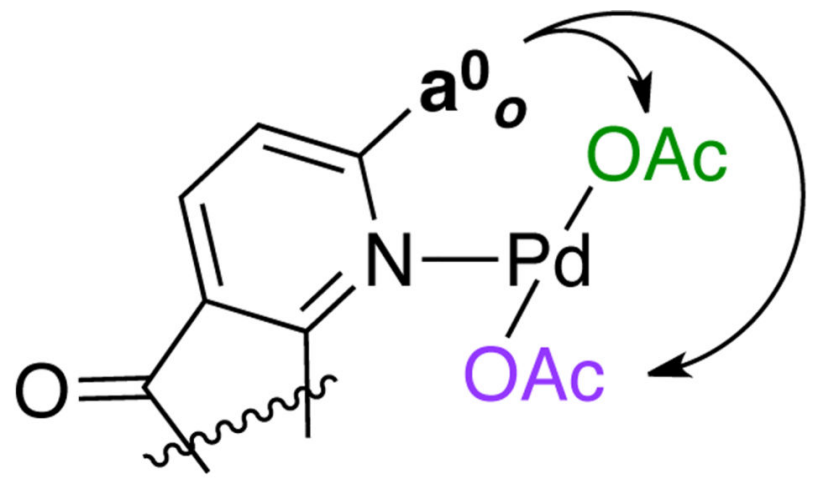

\section{ROE from $\mathbf{a}^{0}{ }_{\mathbf{o}}$ to OAc and OAc $\mathrm{OAc} \neq \mathrm{OAc}$ $\mathrm{DAF}: \mathrm{OAc}: \mathrm{OAc}=1: 1: 2$}

Scheme 5.

Observed DAF-to-OAc ROE Correlations for A. 


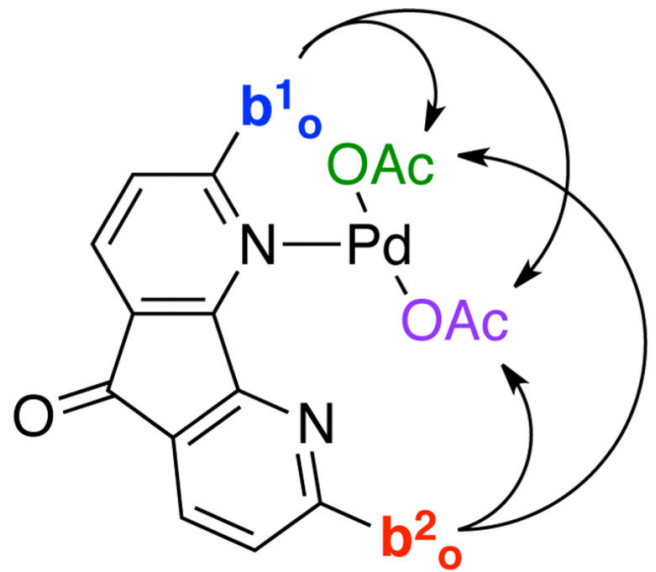

ROEs from $b^{1}{ }_{o}$ and $b^{2}{ }_{o}$ to OAc and OAc $\mathrm{OAc} \neq \mathrm{OAc}$

\section{$\mathrm{DAF}: \mathrm{OAc}: \mathrm{OAc}=1: 1: 1$}

Scheme 6.

Observed DAF to OAc ROE Correlations for $\mathbf{B}$. 


\section{A. DAF $\leftrightarrow$ OAC ROESY}

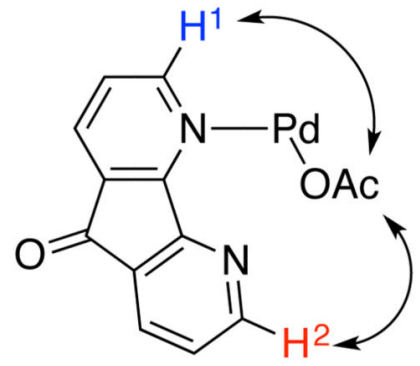

ROEs from $\mathrm{H}^{1}$ and $\mathrm{H}^{2}$ to $\mathrm{OAc}$

\section{B. DAF $\leftrightarrow$ DAF ROESY}
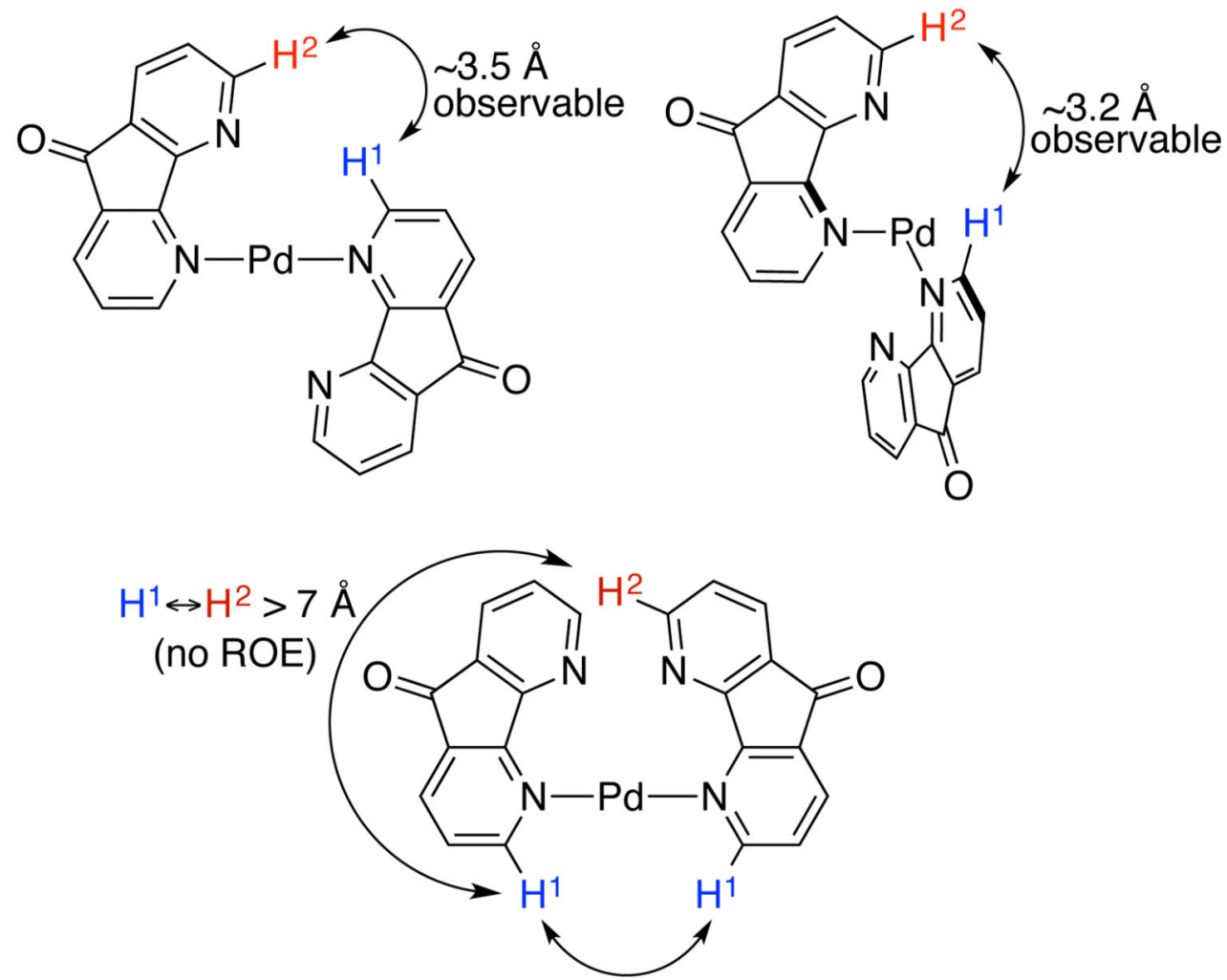

$\mathrm{H}^{1}$ chemically equivalent (no ROE)

Scheme 7.

Observed DAF $\leftrightarrow \mathrm{DAF}$ and DAF $\leftrightarrow \mathrm{OAc}$ ROE Correlations for C-E. 


\section{A. 1D ROESY Spectrum of Chemical Exchange Between D \& E}

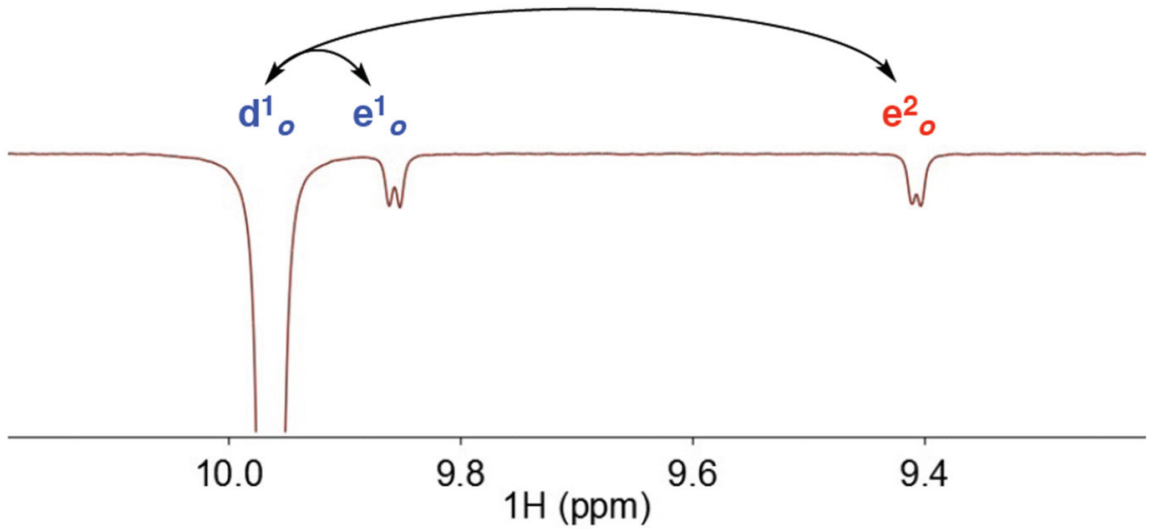

B. Mechanism for Chemical Exchange Between D \& E<smiles></smiles>

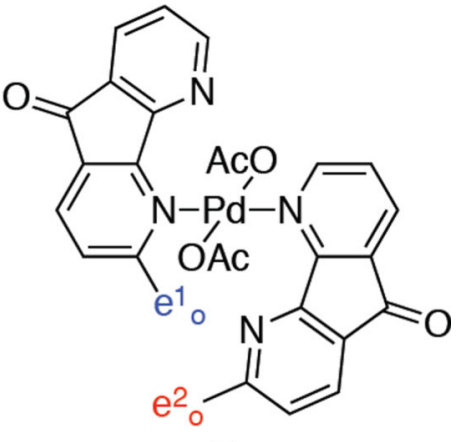

$\Delta \mathrm{G}_{\text {calc: }}: \stackrel{\mathrm{D}}{0.00}$

via

$\mathrm{E}$

$0.15 \mathrm{kcal} / \mathrm{mol}$

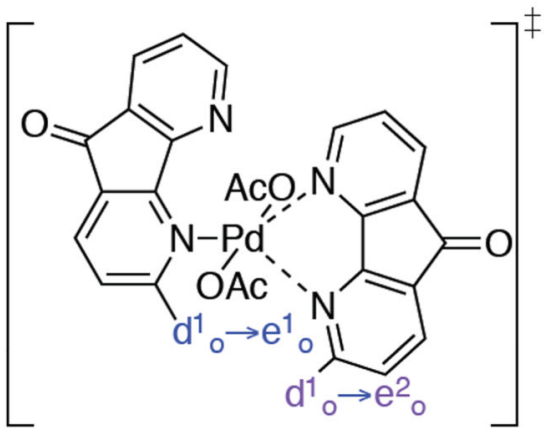

$\mathrm{TS}_{\mathrm{D} \rightarrow \mathrm{E}}$

$10.8 \mathrm{kcal} / \mathrm{mol}(\mathrm{DFT})$

$13.0 \mathrm{kcal} / \mathrm{mol}(\operatorname{expt} \mathrm{l})$

Scheme 8.

Chemical Exchange Process between $\mathbf{D}$ and $\mathbf{E}$. 


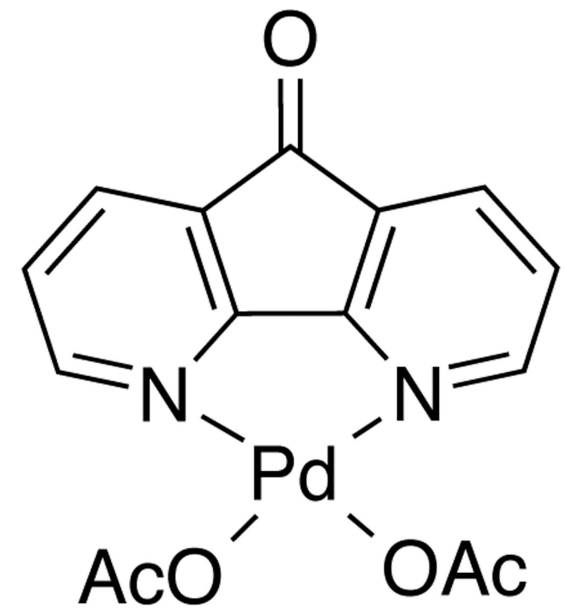

${ }^{15} \mathrm{~N}$ resonance at $\sim 200 \mathrm{ppm}$ $\mathrm{C}_{2}$ symmetry reflects daf rings ROEs to 1 OAc resonance

Scheme 9.

Structure of F Derived from NMR Spectroscopic Methods. 

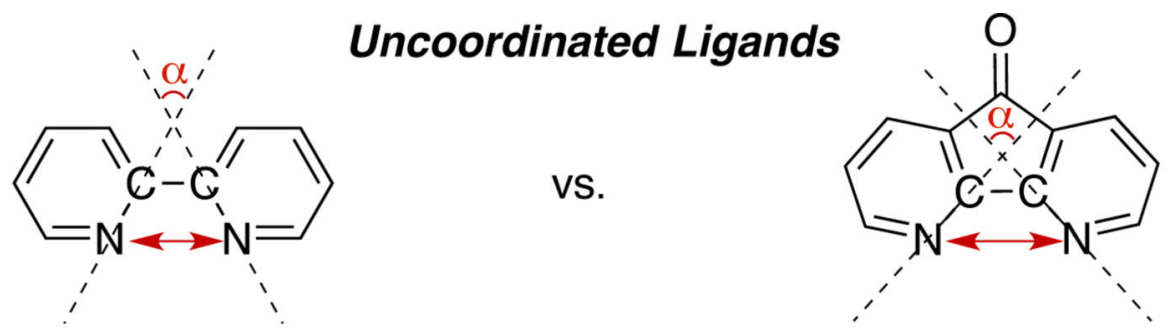

$\alpha: \quad 53^{\circ}$

$N \cdot N$ :

$2.66 \AA$

Pd"l Complexes<smiles></smiles><smiles>CC(C)[n+]1cccc2c1-c1ncccc1C2=O</smiles><smiles>CC(C)[n+]1cccc2c1-c1c(ccc[n+]1C(C)C)C2=O</smiles>

$\kappa^{2}$

$\kappa^{1}$

$\mu$

$\mathrm{LPd}(\mathrm{OAc})_{2}, \mathrm{~L}=$ bpy, Neocuproine

B, C, D, and E

74-76 ${ }^{\circ}$

3.10-3.12 A

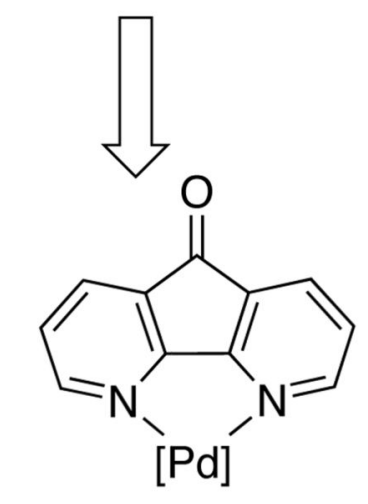

$\kappa^{2}$

$\mathbf{J}$ (and $\mathbf{H}$ )

$60^{\circ}\left(61^{\circ}\right)$

2.76 (2.78) ^
A, G, I, and L

$82-84^{\circ}$

$3.22-3.32 \AA$

Scheme 10.

Structural Comparison of 2,2'-Bipyridine, DAF and Corresponding PdII Complexes. 


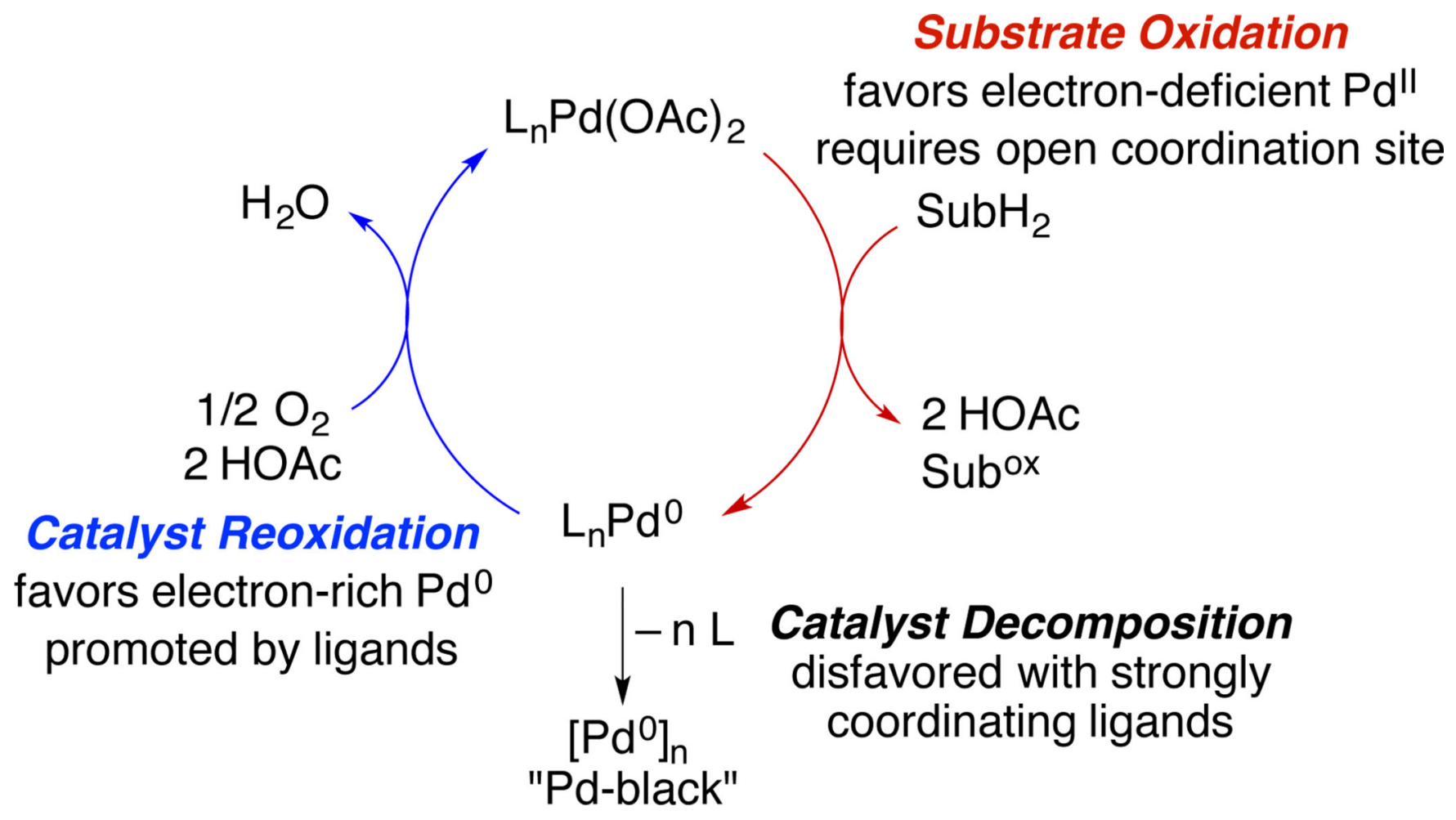

Scheme 11.

Representative Catalytic Cycle for Pd-Catalyzed Aerobic Oxidations 


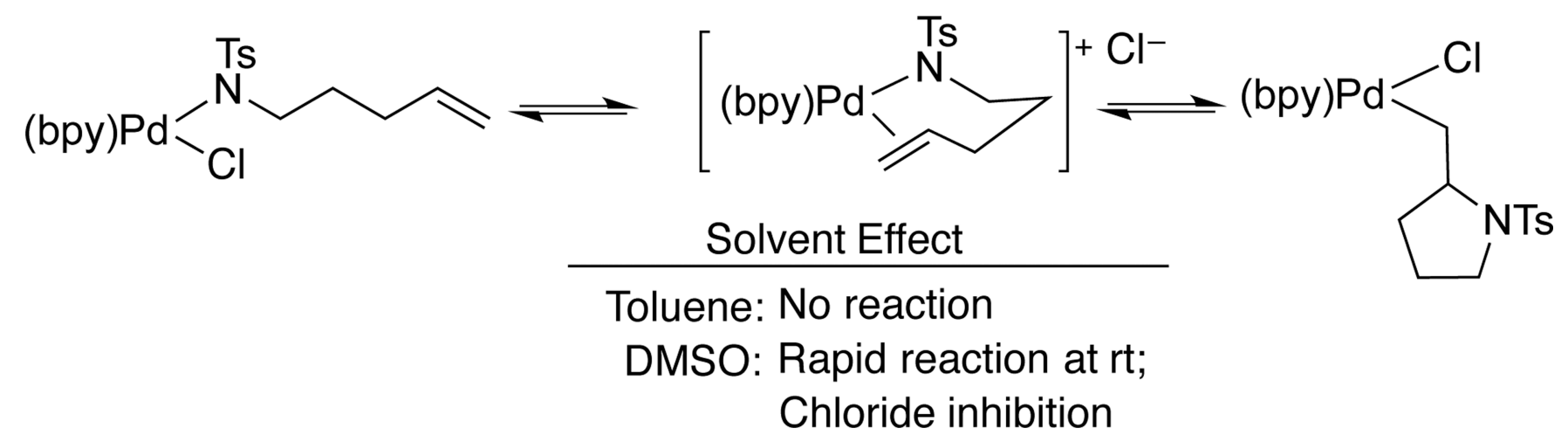

Scheme 12.

Solvent Effect on X-Type Ligand Dissociation 

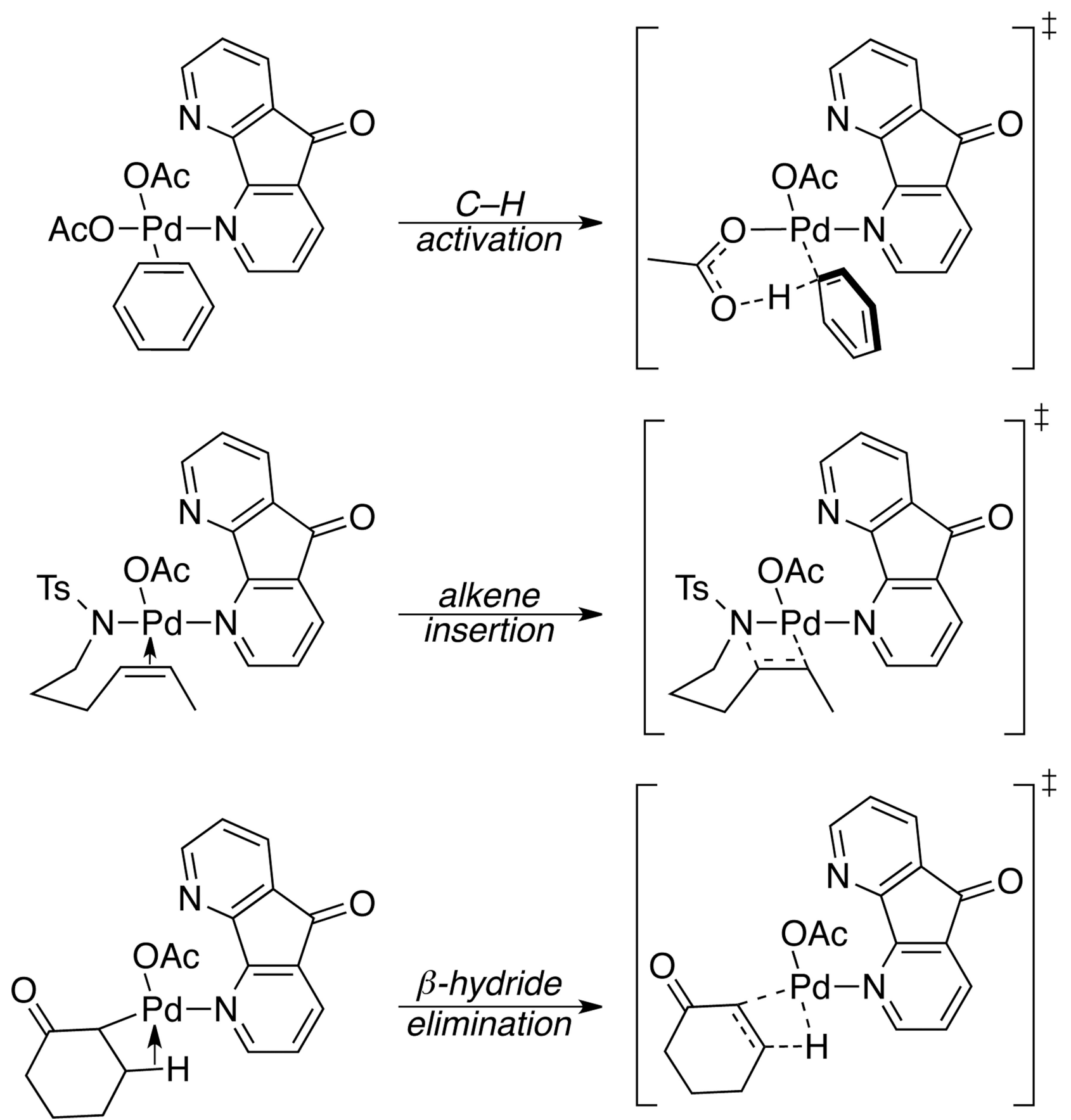

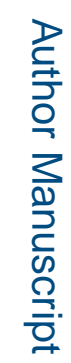

Scheme 13.

Proposed Intermediates and Transition States in DAF-Promoted Catalysis. 
A.
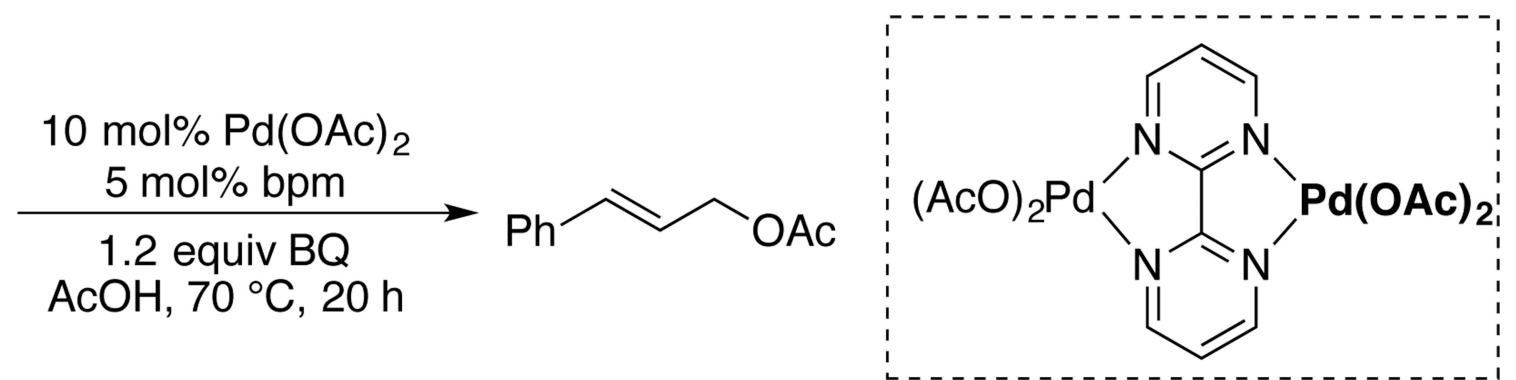

B.<smiles>C=CCc1ccccc1</smiles><smiles>c1ccccc1</smiles>

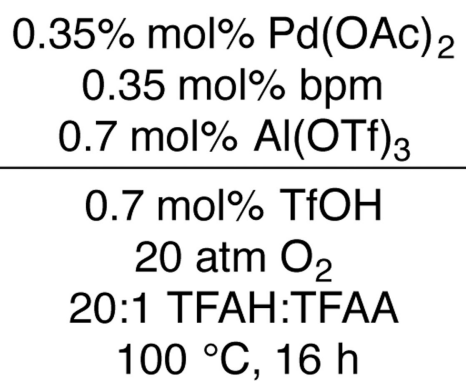

Scheme 14.

$\mathrm{Pd}(\mathrm{bpm})(\mathrm{OAc})_{2}$-Catalyzed C-H Oxidation Reactions Promoted by Ligand Coordination to a Second Metal. 
Table 1

Assignments of $\mathbf{C}-\mathbf{E}$ from NMR Spectroscopic and DFT Results.

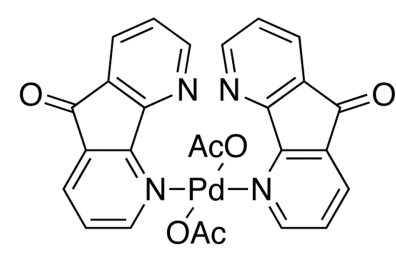

1

DAF-DAF relation:

Static Point Group:

$\Delta \mathrm{G}_{\mathrm{rel}}(\mathrm{kcal} / \mathrm{mol})$ :

Assignment:

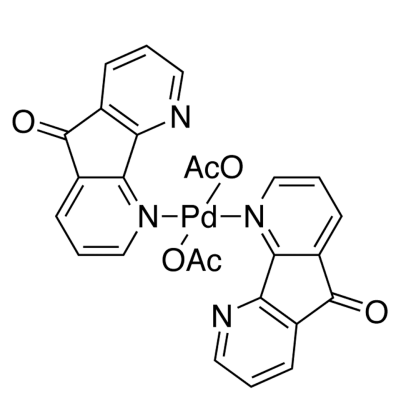

2

trans/anti

$C_{\mathrm{i}}$

0.15

E

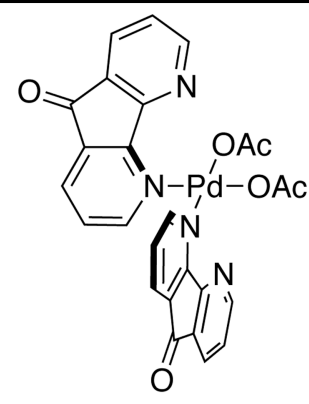

3

cis/anti

$C_{2}$

1.54

C

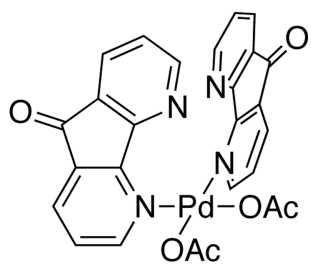

4

cis/syn

$C_{\mathrm{S}}$

6.02

not observed 